\title{
Angstkonstruktionen zwischen „sinnvoller Vorsicht und sinnloser Panik“
}

\author{
Eine korpuspragmatische Studie zu Sprachgebrauchsmustern \\ im Umfeld des Lexems Angst in Online-Zeitungen
}

\begin{abstract}
Dieser Beitrag geht von der These aus, dass Angst eine kulturell geprägte Emotion ist. Analytisch greifbar wird diese kulturelle Prägung durch rekurrente sprachliche Muster, die auch diachron variieren können und sich in besonderer Weise in massenmedialen Texten als profilierten Orten des gesellschaftlichen Angstmanagements beobachten lassen. Im Rahmen einer korpuspragmatischen, datengeleiteten Studie wird im vorliegenden Beitrag das Inventar der Angstkonstruktionen, die für aktuelle Diskurse relevant sind, ermittelt. Auf der Basis umfangreicher Korpora, bestehend aus Artikeln der Onlinzeitungen DIE ZEIT und DER SPIEGEL, werden dazu rekurrente sprachliche Muster im Umfeld des Lexems Angst erhoben und als potentielle Angstkonstruktionen anhand ihrer Kontexte näher untersucht. Die Ergebnisse liefern einen Beitrag zu einer erweiterten Grammatik der Angst, welche die Konturen der aktuellen Angstkultur hervortreten lässt.
\end{abstract}

This work is focusing on the notion of fear as a cultural construct. Analytical evidence of the cultural imprint is given by recurrent patterns in language that can vary over time. Those patterns can be investigated especially by analyzing articles of mass media, since they are intended to be part of a fear management by making fear a subject of discussion. By following that notion, a corpus pragmatic and corpus-driven study will be presented with the general aim to identify a set of fear constructions as part of the current discourse. Based on extensive corpora of articles from the online newspapers DIE ZEIT and DER SPIEGEL, recurrent language patterns in the context of the lexeme fear were collected. As potential constructions of fear, those patterns are moreover investigated by focusing on their context. Finally, the results lead to an extended grammar of fear which also allows further insights into the current culture of fear.

Anmerkung: Der zitierte Ausschnitt ist Teil der Unterüberschrift eines ZEIT-Artikels mit dem Titel „Angst ist auch ein Virus“ zum Umgang mit dem Coronavirus in Deutschland. Er ist am 04. März 2020 erschienen und online abrufbar, unter: https://www.zeit.de/2020/11/corona virus-deutschland-infizierte-quarantaene-angst (zuletzt aufgerufen am 12.08.2020). 


\title{
1 Zur gesellschaftlichen Bedeutung der Angst
}

\begin{abstract}
Wie auch immer sich der Verlauf von Covid-19 in den kommenden Wochen und Monaten entwickelt: Verfallen Sie nicht in Panik! Das ist ernst gemeint, denn Panik ist unangemessen - Sorge hingegen aktuell leider nicht: Mit jedem Tag zeigt sich, dass sich das neuartige Coronavirus Sars-CoV-2 viel stärker außerhalb Chinas ausbreitet als gehofft, derzeit gibt es Fälle in 37 Ländern. [...] Die Zeit, das Virus durch die vorübergehende Isolation einzelner Erkrankter und ihrer Kontakte in Schach zu halten, läuft ab. Wahrscheinlich muss man sogar sagen: Sie ist längst verstrichen. Das kann einem Angst machen. (DER SPIEGEL, 27.02.2020 $)^{1}$
\end{abstract}

In der medialen Berichterstattung zur Coronavirus-Pandemie ist eine z. T. metasprachliche Auseinandersetzung zur Angemessenheit von Angst und semantisch ähnlichen Begriffen beobachtbar, wie der zu Beginn zitierte Ausschnitt eines Kommentars im SPIEGEL verdeutlicht, dessen Argumentation auf der Definition von Panik aus dem Duden aufbaut. Panik wird als unangemessen gekennzeichnet, Sorge sei dies hingegen nicht. Und auch die Angst wird angesichts der Unsicherheit, ob das Virus in Schach zu halten ist, als nachvollziehbar bzw. als zu erwarten charakterisiert. Ähnlich verhält es sich in einem ZEITArtikel, der in der Überschrift des vorliegenden Beitrages zitiert wurde. Der sinnvollen Vorsicht wird die sinnlose Panik gegenübergestellt. Wie die nachfolgenden Ausführungen verdeutlichen werden, stellen die thematisierte Angst, Sorge und Panik i.d. R. keine Beschreibungen einer unmittelbar wahrgenommenen Emotion bzw. des Emotionsausdrucks, sondern Formen der sprachlichen Konstruktion von Angst bzw. Ängsten dar. Die zitierten Zuschreibungen angemessen/ unangemessen und sinnvoll/ sinnlos im Rahmen des Diskurses zur Angemessenheit bzw. Unangemessenheit von Angst prägen - sofern diese rekurrent erfolgen - die Bedeutung der einzelnen Begriffe. Darüber hinaus können verschiedene Formen der sprachlichen Konstruktion von Angst selbst die Angst im Sinne einer Angstspirale verstärken (vgl. Luhmann 1990: 238) oder das ,Zeigen“ bzw. die Ausdrucksformen der Angst im Sinne ihrer Manifestation beeinflussen (vgl. etwa die „Feeling Rules“ nach Hochschild 1979: 563-566). Demzufolge besitzen Angstkonstruktionen eine hohe gesellschaftliche Relevanz, die es zu ergründen gilt und auf die im vorliegenden Beitrag exemplarisch eingegangen wird.

1 Abrufbar unter: https://www.spiegel.de/gesundheit/diagnose/coronavirus-panik-istun-angemessen-sorge-leider-nicht-kommentar-a-ee36b757-1c94-4263-a4b4-fb03699504f6 (zuletzt aufgerufen am 25.08.2020). 
Die dem Beitrag zugrundliegende Studie ist dem Bereich der Korpuspragmatik zuzuordnen und verfolgt die übergeordnete Zielstellung, das Inventar von Angstkonstruktionen, die für aktuelle Diskurse relevant sind, zu ermitteln und anhand der Kontexte eine Bestimmung der Funktion dieser Konstruktionen vorzunehmen. Dies erfolgt ausgehend von beobachtbaren bzw. berechenbaren Mustern, „[...] in die sich ein Gebrauchswert eingeschrieben hat [...]“ (Scharloth/ Bubenhofer 2012: 196) - in denen sich also gesellschaftliche Relevanzsetzungen niederschlagen. Dabei folge ich der Auffassung Müllers (2015), der bei einem Muster dann von einer Konstruktion spricht, „[...] wenn ihm mit korpuspragmatischen Mitteln ein Kontextualisierungspotenzial nachgewiesen werden kann, wenn also eine Korrelation zwischen Ausdrucksform und mindestens einer Kontextdimension ${ }^{2}$ sprachstatistisch nachweisbar ist und sich in der exemplarischen Verwendungsanalyse eine oder mehrere Diskursfunktionen ${ }^{3}$ beschreiben $^{-}$ lassen.“ (ebd.: 118)

Im folgenden Kapitel wird zunächst auf die kulturelle Bedeutung des Lexems Angst Bezug genommen, die die Grundlage des Beitrages bildet. Anschließend werden in Kapitel 3 die Erkenntnisse einiger Studien zu semantischen Kookkurrenzen, grammatischen Strukturen und der Funktion des Lexems Angst sowie zu weiteren Lexemen aus dem semantischen Feld der Angst in verschiedenen Diskursen wiedergegeben. Diese dienen als Grundlage für die Interpretation der Ergebnisse der sich anschließenden Studie des Beitrags. Die Basis für die Analyse, die in Kapitel 4 wiedergegeben wird, bilden zwei Korpora mit Texten der Online-Präsenz der Zeitungen DIE ZEIT und DER SPIEGEL. Zunächst soll die Semantik des Lexems Angst sowie einiger Synonyme und funktionaler Äquivalente anhand von Kollokationen und Word Embeddings untersucht werden. In einem zweiten Schritt werden charakteristische Mehrworteinheiten im Umfeld des Lexems Angst ermittelt und wiederum anhand ihrer Kontexte funktional bestimmt. Beide Untersuchungsschritte erfolgen in einem hohen Maße datengeleitet mit dem Ziel, rekurrente sprachliche Muster $\mathrm{zu}$ ermitteln und als Formen der kulturellen Bedeutungszuschreibung zu deuten.

2 Müller (2015: 87-96) führt u. a. die Kontextebenen ,Situation‘, ,Kotext‘, ,soziale Sprecherrolle' und ,thematischer Diskurs' an.

3 Dabei versteht Müller (2015: 60-62) ,Diskurs‘ grundsätzlich im offenen Sinne als ,Sprachgebrauch'. 


\section{Medien als Orte der Angstkultur und des Angstmanagements}

Lickhardt (2013: 189) zufolge ist eine genaue Bedeutungsbestimmung des Lexems Angst grundsätzlich erschwert, da Angst als Begriff, ebenso wie die Emotionsbegriffe im Allgemeinen, keinen konkreten Gegenstand der Entsprechung bzw. keine unmittelbar fassbare Referenz besitzt. Käuser (2013: 145) schlussfolgert in diesem Zusammenhang, dass aus der Unbestimmtheit des Objekts die Unbestimmtheit des Begriffes resultiert. In ihrer phänomenalen Grundstruktur bezieht sich die Angst auf einen „Konflikt zwischen einer leiblichen Einengung und einem gegen sie gerichteten Fluchtimpuls“ (Fuchs/Micali 2013: 52). Demnach erscheint es nicht verwunderlich, dass die ,Enge“ in vielen Sprachen den semantischen Kern des Angst-Begriffes bildet. So verweist etwa das lateinische angor auf ,Würgen, Beklemmung, Angst‘ (vgl. ebd. sowie Böhme 2009: 168f.). In ihrer Form als Affekt besitzt die Angst eine überlebenssichernde Funktion. Sie stößt uns plötzlich zu und aktiviert wichtige Flucht- und Abwehrfunktionen des Organismus (vgl. Fuchs/Micali 2013: 53f.). Im Rahmen der gesellschaftlichen Entwicklung und damit einhergehender Schutzmaßnahmen konnten grundlegende Gefahren minimiert werden, sodass die durch natürliche Bedrohungen und körperliche Gewalt ausgelöste primäre Form der Angst „[...] in der Neuzeit durch innengeleitete, vom Menschen selbst geschaffene Ängste ersetzt [...]“ (Käuser 2010: 18) wurde. Die Menschen bringen die Ängste selbst, also „autorefentiell und medienkulturell“ (Käuser 2013: 142) zum Ausdruck. Käuser versteht unter medialen Ausdrucksformen vorrangig die „Sichtbarkeit und Körperlichkeit“ (ebd.: 143) des Phänomens der Angst in audiovisuellen Medien wie Filmen und in der Kunst. Demgegenüber seien die Akteure des theoretischen und publizistischen Diskurses bemüht, mit Hilfe von „diskursiven Plausibilisierungen und Erörterungen“ (ebd.: 145) die Angst „zu mildern“ (ebd.). Dabei kann der gegenteilige Effekt erreicht werden, indem mit den genannten Maßnahmen zur Angstmilderung die Angst verstärkt wird (vgl. Luhmann 1990: 238). An dieser Stelle ist weiterhin zu ergänzen, dass autoreferentielle Darstellungen der Angst wie in Form von Interviews, die Schilderungen des eigenen Angsterlebens enthalten, ebenfalls einen wichtigen Platz im publizistischen Diskurs einnehmen, wie Beispiele in den folgenden Kapiteln verdeutlichen werden. Käuser (2010) schlussfolgert in diesem Kontext: „Angst erzeugt die Entwürfe und Diskurse ihrer eigenen Beschreibung [...].“ (ebd.: 21) Durch „kulturelle Vorgaben“ (Linke 2011: 28) ist die Wahl der Ausdrucksformen für Angst eingeschränkt. Dabei wird die kulturelle Prägung dieser Emotion in spezifischen Musterbildungen auf der 
Textebene, jedoch darüber hinaus auch auf der Wort- und Satzebene deutlich (vgl. ebd.). ${ }^{4}$ Linke (1998) konstatiert im Allgemeinen, dass „[...] Gefühl bzw. Gefühle nicht nur als individualpsychologische Größen $\mathrm{zu}$ interpretieren, sondern darüber[ ]hinaus kulturell geprägt sind und sozialspezifischen Normierungen und Habitualisierungen unterliegen. Die Gefühlsprogrammatik einer Epoche bzw. einer bestimmten sozialen Gruppierung dürfte bis zu einem gewissen Maß das individuelle Erleben überlagern und überformen [...].“ (ebd.: 234, Herv. im Original) Dabei können „Veränderungen im Emotionswortschatz und in den Traditionen des Sprechens über Emotionen“ (Linke 2009: 173) als „Belege für Veränderungen in der Konzeptualisierung, allenfalls auch in der Erlebnisqualität von Emotionen“ (ebd.) gedeutet werden.

Neben der Angst selbst unterliegen auch die Techniken zur Angstbewältigung einer kulturellen Prägung (vgl. Böhme 2009: 171). Hierzu bemerkt Böhme (2000): „Ob real oder symbolisch, räumlich oder zeitlich: Distanzierung und Selbstdistanzierung sind in allen Angstbewältigungstechniken die entscheidende Leistung.“ (ebd.: 12) Neben der Distanzierung kann das Sprechen über Angst der Angstbewältigung dienen. Wie bereits mit Bezug auf Käuser (2013) verdeutlicht wurde, ist letztere Bewältigungsstrategie im publizistischen Diskurs anzutreffen. Äußerungen, die sich auf die Thematisierung, die genauere Bestimmung und Klassifizierung der Angst sowie auf die Ableitung von Maßnahmen zur Angstminderung beziehen, verstehe ich als kommunikative Formen der Bearbeitung der Angst und somit des Angstmanagements.

Um die Vorstellung von Angst als kulturell geprägter Emotion über die Grenzen des Begriffs hinaus zu erweitern, verwende ich den Begriff der Angst$k$ ultur $^{5}$, der auch die kulturelle Prägung des Angstmanagements einschließt. Dabei stütze ich mich auf Böhme (2009), der konstatiert, „[...] daß die menschlichen Ängste kulturell überformt, stilisiert, diszipliniert, modifiziert, anästhesiert oder gar künstlich erregt werden, also historisch ausdifferenzierte Gefühlskulturen entstehen [...]“ (ebd.: 171), die „kulturspezifische Bewältigungsmuster der Angst“ (ebd.) einschließen. In einer diachronen Perspektive kann schließ-

4 Diese Annahme fußt auf der allgemeinen These Linkes (2011), „[...] dass Musterbildungen im Sprachgebrauch einen wichtigen ,Ort“ der Verschränkung von Kultur und Sprache [...] darstellen.“ (ebd.: 27)

5 In diesem Zusammenhang verstehe ich Kultur wie Schröter (2016) „[...] erkenntnisoffen als etwas Menschliches, Komplexes, Zusammenhängendes, das von einem Kollektiv getragen wird, welches so groß ist, dass nicht alle daran beteiligten Menschen einander kennen, etwas, das aus kognitiven Elementen, Aktivitäten sowie Artefakten bestehen kann und das anders sein könnte, als es ist.“ (ebd.: 381, Herv. im Original) 
lich von verschiedenen Angstkulturen, bezogen auf spezifische Zeiträume, gesprochen werden. Dies wird durch die Aussage Schmieders (2013) gestützt:

Kaum ein Zweifel dürfte darüber bestehen, dass der Eintritt in das nukleare Zeitalter auch zu neuen Kulturen der Angst geführt hat [...]. Der Atompilz wurde zu einem neuen Kollektivsymbol, mit dem sich das Bewusstsein einer Zeitenwende und einer Veränderung der Conditio humana verband [...]. Die atomare Situation wurde zum Schauplatz einer Vielzahl von Debatten und Kommunikationsstrategien, bei denen es immer auch um die Bearbeitung der Angst ging, wobei die Angst, je nach Perspektive, als psychologische Bedrohung oder als politische Ressource in Betracht gezogen wurde. (ebd.: 201, Herv. im Original)

Auch Böhme (2009) führt aus, dass man „Epochen an dem charakteristischen ,Stil` ihrer Ängste“ (ebd.: 171) erkennen könne. Biess (2019: 18) nahm kürzlich den Angstdiskurs zum Ausgangspunkt, um die Geschichte der Bundesrepublik von den Anfängen in der Nachkriegszeit bis hin zur gegenwärtigen Lage zu rekonstruieren. Diese beschreibt er als eine „Geschichte aufeinanderfolgender Angstzyklen“ (ebd.: 12). Dabei kann der Begriff der Angstzyklen weitgehend mit dem in diesem Beitrag verwendeten Begriff der Angstkulturen gleichgesetzt werden. Biess' Untersuchungsmethode basiert auf empirischen, qualitativen Fallstudien, beispielsweise auf der Basis von Zeitungsberichten, Leserbriefen oder Tagebuchaufzeichnungen. Schließlich begreift auch Wengeler (2019) Zukunftsangst als spezifische Form bzw. Ausprägung der Angst als „KulturPhänomen“ (ebd.: 95), „[...] das sich möglicherweise als diskursive Größe [...] in Deutschland über lange Zeiträume hinweg gehalten hat und das sich daher für eine diachrone Längsschnittstudie zu erforschen lohnt.“ (ebd.) Im diachronen Vergleich könnte Wengeler zufolge auf der Basis verschiedener themenspezifischer Diskurse untersucht werden, welche Rolle die „öffentliche Konstruktion von Ängsten“ (ebd.: 96) mit sprachlichen Mitteln im jeweiligen Diskurs und Zeitraum spielt und welche Gegenstände der Angst thematisiert werden.

Im vorliegenden Beitrag soll die gegenwärtige Angstkultur in den Blick genommen und auf der Grundlage von Zeitungsartikeln exemplarisch untersucht werden. Dies erfolgt in Anlehnung an Linke auf der Basis von rekurrenten sprachlichen Mustern. Im Folgenden sollen einige Studien wiedergegeben werden, die auf einem ähnlichen methodischen Ansatz beruhen.

\section{Studien zu Angstkonstruktionen}

Bisher liegen nur wenige Untersuchungen vor, die sich mit der sprachlichen Konstruktion von Angst ausgehend von rekurrenten Sprachgebrauchsmustern 
beschäftigen. Die Erkenntnisse einiger Studien werden im Folgenden kurz erläutert, da sie die Deutung der Ergebnisse der in Kapitel 4 wiedergegebenen Studie unterstützen.

Im Rahmen einer diskurshistorischen Analyse untersucht Filatkina (2015) auf der Basis von SPIEGEL ONLINE-Artikeln sprachliche Formen der medialen Konstruktion des Begriffs Zukunftsangst im Zeitraum von 1970 bis 2013. Anhand zahlreicher Belegstellen zeichnet Filatkina nach, wie sich das semantische Feld der Zukunftsangst im Laufe der Zeit verändert hat, indem neue Themen bzw. Kontexte hinzutreten, während andere in den Hintergrund treten oder nicht mehr belegt sind. Während sich die Zukunftsangst zunächst vor allem auf den technischen Fortschritt bezog (vgl. ebd.: 88), wird diese im weiteren Verlauf etwa mit Unsicherheiten der ehemaligen DDR-Bevölkerung nach der Wende (vgl. ebd.: 95), der zunehmenden Verschmutzung der Umwelt und damit einhergehenden Krankheiten (vgl. ebd.: 101f.) sowie der Angst vor dem Islam (vgl. ebd.: 115) in Beziehung gesetzt. Insgesamt sind die Inhalte des semantischen Feldes vielfältig, wobei sich einige kontinuierliche Themen wie „schlechte beziehungsweise fehlende berufliche Perspektiven als Folge von Krisen“ (ebd.: 120) abzeichnen. Auch einige sprachliche Mittel werden in kontinuierlicher Weise gebraucht, um die Zukunftsangst als dramatisch und zweifellos gegeben erscheinen zu lassen (vgl. ebd.: 121). Filatkina weist in diesem Zusammenhang darauf hin, dass Zukunftsangst bereits von Beginn des Untersuchungszeitraumes an „apodiktisch festgestellt“ (ebd.: 119) wird, sodass keine Zweifel an der Existenz bestehen sollen (vgl. ebd.). Dabei dienen Studien zur Angst der Deutschen als wichtige Stütze und betonen die Allgegenwärtigkeit der Angst, die demzufolge nicht bestritten werden kann (vgl. ebd.: 105). Außerdem identifiziert Filatkina in den Jahren nach 2000 im medialen Diskurs einen „eigenen kritischen Metadiskurs über den Begriff Zukunftsangst“ (ebd.: 115). Ferner wird Zukunftsnagst nicht nur als Folge von Krisenereignissen und als Charakterisierung der Stimmungslage eines Kollektivs, sondern auch als Ursache für Rechtsextremismus und Kriminalität thematisiert (vgl. ebd.: 120) und im Sinne einer ,Kultur des Verdrusses‘ (ebd.: 121) bezogen auf die gesamte Bundesrepublik als Kulturphänomen konstruiert.

Einige Ergänzungen in Bezug auf die soeben dargestellte Untersuchung finden sich bei Filatkina (2017). Auszüge des unveröffentlichten Manuskripts werden auch von Wengeler (2019) zitiert und sind in der Einleitung dieses Sammelbandes enthalten. Filatkina erweitert dabei den Zeitraum der Untersuchung bis auf das Jahr 2017 und ergänzt die Studie durch Belege des Deutschen Referenzkorpus (DeReKo). Durch die Ermittlung rekurrenter Sprachgebrauchsmuster auf lexikalisch-semantischer und morphosyntaktischer Ebene in Diskur- 
sen über negativ besetzte Zukunftsentwürfe entwickelt Filatkina die Grundzüge einer Grammatik der Angst. Einige sprachliche Mittel dieser Grammatik seien an dieser Stelle bezugnehmend auf die Seiten 102f. bei Wengeler (2019) sowie die Beiträge Filatkinas (2015 und 2017) kurz skizziert. So kommt das Lexem $\mathrm{Zu}$ kunftsangst häufig „[...] in Verbalphrasen vor, vor allem mit atelischen durativen Handlungsverben, [...] die dynamische Vorgänge beschreiben und keinen Kulminations- oder Endpunkt voraussetzen (treiben, herrschen, [...], plagen, peinigen) bzw. graduelle Änderungen versprachlichen (wachsen, zunehmen).“ (Filatkina 2017) Dynamische Vorgänge werden weiterhin über die „parataktische Aneinanderreihung kurzer Sätze, Nominalphrasen oder Einzellexeme“ (ebd.) und zum Teil durch Konstruktionen wie so schlimm wie nie zuvor in ihrer Dramatik im Sinne eines Singularitätstopos gesteigert, wobei die Zukunftsangst zugleich als typisch deutsches Phänomen charakterisiert wird (vgl. ebd. sowie Filatkina 2015: 105). Darüber hinaus sind für Zukunftsangst-Konstruktionen Genitivattribute typisch, die auf die Träger der Zukunftsangst verweisen und eine im Laufe der Zeit abnehmende Tendenz aufweisen. Als Attribute treten v. a. Bezeichnungen für Gruppen von Personen auf, die über bestimmte Begriffe teilweise als beruflich oder geographisch zusammengehörig gekennzeichnet werden. Filatkina (2015: 90) deutet diese Kollektiva als Mittel zur „Dramatisierung des Ausmaßes der Zukunftsangst“. Zum Teil werden die Träger durch Präpositionalphrasen und Relativsätze eingeführt und beschrieben. Diese Beschreibungen bleiben insgesamt aber vage. Während Zukunftsangst in zunehmendem Maße mit schlimmen Ereignissen im Sinne einer Aufzählung verbunden wird, überwiegen bei Angst Präpositionalphrasen mit vor + Objekt, die den Gegenstand der Angst benennen und diese somit konkretisieren. AuBerdem verweist Filatkina (2017) auf die Besonderheit, dass Zukunftsangst häufig im Umfeld von Adversativ- und Konzessivsätzen auftaucht, die mit wenn, obwohl und trotz eingeleitet werden. Inhaltlich wird deutlich, dass durch diese Sätze „positive Jetzt-Situationen“ konstruiert werden, die anschließend widerlegt werden. Filatkina (2015: 90) verweist an dieser Stelle, bezugnehmend auf Wengelers Theorie der Topoi, auf den Gebrauch des Trotz-Topos, der auf ein schlimmes Ende im Sinne negativer Zukunftserwartung verweist.

Die thematisierte Grammatik der Angst kann durch eine Studie Holzingers (2018) erweitert werden. Dieser setzt sich mit „Strukturen des Typs [mit + Substantiv] in adverbialer Funktion [...] im semantischen Feld der Angst“ (ebd.: 229) auf der Basis des Deutschen Referenzkorpus (DeReKo) auseinander. Die Wortverbindungen werden dabei auf rekurrente Strukturen hin untersucht, die neben der wörtlichen Bedeutung auf semantische und pragmatische Besonderheiten hinweisen (vgl. ebd.: 230). Unter den verbalen Kollokationen der adver- 
bialen Verbindung mit Angst finden sich an oberster Stelle reagieren und begegnen. Die Angst stellt Holzinger zufolge somit die Reaktion auf etwas Vergangenes dar und ist objektbezogen (vgl. ebd.: 232f.). Weiterhin treten häufig Verben mit dem Präfix entgegen- wie entgegensehen, entgegenblicken oder entgegentreten in Verbindung mit der untersuchten Adverbialphrase auf, wobei die Wahrnehmungsverben überwiegen. Holzinger sieht in den genannten Konstruktionen einen „klaren Zukunftsbezug“ (ebd.: 233). Verschiedene Beispiele sollen illustrieren, dass „konkrete Gründe“ (ebd.: 244) der Angst häufig im Kotext genannt werden. Holzinger differenziert hierbei jedoch nicht zwischen Träger und Gegenstand, wie die folgende Auflistung nahelegt: „Bedrohung, Gefahr, Gewalt, Opfer, Krankheit, Tod, Leiden und Veränderung“ (ebd.). Darüber hinaus identifiziert Holzinger das typische Muster ,mit X und Y‘, das am häufigsten in der Form mit Angst und Schrecken, aber auch in der Form mit Angst und Sorge oder mit Angst und Panik realisiert wird. Diese Paarformeln besitzen Holzinger zufolge unterschiedliche Idiomatizitätsgrade, wobei er ihnen grundsätzlich eine intensivierende Wirkung zuschreibt (vgl. ebd.: 236-238). Holzinger verweist im Kontext der Paarformeln auf Realisierungen mit weiteren Substantiven aus anderen Bedeutungsbereichen wie mit Angst und Wut, geht jedoch nicht genauer darauf ein (vgl. ebd.: 236). Folgt man Nussbaum (2019), die etwa „Zorn als Kind der Angst“" (ebd.: 110) beschreibt, könnte sich aus diesen Formen eine eigene Dynamik oder Kausalität ergeben, die es anhand von Textbelegen und den unmittelbaren Kontexten zu ergründen gilt.

Im Folgenden sollen die Erkenntnisse der vorangegangenen Studien durch eine datengeleitete Untersuchung ergänzt werden.

\section{Eine datengeleitete Studie zu Angstkonstruktionen in Online-Zeitungen}

\subsection{Zur Untersuchungsmethode}

Ähnlich zur geschilderten diskurshistorischen Analyse Filatkinas (2015) bildet ein Lexem den Ausgangspunkt der Untersuchung, das Lexem Angst. Die Untersuchung basiert dabei auf einem korpuspragmatischen Verfahren, das in einem möglichst hohen Maße corpus-driven erfolgen soll (vgl. Bubenhofer/Scharloth 2013: 149). Auf der Basis zweier Korpora, die im Folgenden noch genauer vorgestellt werden, werden sprachliche Muster im Umfeld des Lexems Angst ermittelt. Diese sprachlichen Muster können schließlich „[...] als Ergebnis rekurrenter Sprachhandlungen der Autorinnen und Autoren der im Korpus enthaltenen 
Texte bzw. der sie autorisierenden Institutionen und Gruppen [...]“ (ebd.: 148) angesehen werden. Die Sprachhandlungen verweisen darüber hinaus auf soziales Handeln und sind Ausdruck der Kultur (vgl. Bubenhofer 2009: 4 sowie 41f.). Der Vorteil dieses Vorgehens besteht darin, dass die Ergebnisse nicht nur dazu dienen, bestehende Hypothesen abzulehnen oder zu bestätigen. Vielmehr regen die Ergebnisse zur Bildung neuer Hypothesen oder Analysekategorien an (vgl. Bubenhofer/Scharloth 2013: 149). Das heißt, auf Hypothesen, die den Ausgangspunkt einer Untersuchung im Sinne eines corpus-based Paradigmas bilden, wird in der vorliegenden Studie weitgehend verzichtet. Dennoch wird, wie bereits erwähnt, im Rahmen der Deutung der Ergebnisse auf die Erkenntnisse der vorangegangenen Studien zu Angstkonstruktionen zurückgegriffen. Einige Zwischenergebnisse führen zudem zu Hypothesen, die erneut zu prüfen sind, sodass für die vorliegende Untersuchung von einer Mischform bzw. einem „Scharnier“ (Bubenhofer 2009: 149) zwischen corpus-driven und corpus-based gesprochen werden kann. Das übergeordnete Erkenntnisinteresse besteht darin, die durch Filatkina eingeführte Grammatik der Angst auf die bereits ermittelten Angstkonstruktionen hin zu überprüfen und um neue Konstruktionen zu erweitern. Darüber hinaus soll ein methodischer Ansatz vorgestellt werden, der den Fokus auf die Exploration neuer Angstkonstruktionen legt und sich sowohl für synchrone als auch für diachrone Studien eignet. Neben dem Lexem Angst sollen dabei auch dessen Ko(n)texte entscheidend sein. ${ }^{6}$

\subsection{Korpusgrundlage}

Als Datengrundlage der folgenden Analysen dient ein Korpus, das aus sämtlichen Artikeln der Online-Zeitschriften DIE ZEIT und DER SPIEGEL aus dem Zeitraum von 2013 bis 2020 zusammengestellt wurde. Kostenpflichtige Artikel wurden dabei ausgeschlossen. Bezogen auf das Jahr 2020 sind Artikel bis einschließlich des 08.06.2020 enthalten. Die relevanten URLs wurden mit einem eigenen Perl-Skript zusammengestellt und anschließend mit Hilfe des Tools Trafilatura in der Version v0.5.0 $0^{7}$ heruntergeladen. Der Vorteil dieses Tools be-

6 Filatkina (2017) weist in diesem Zusammenhang darauf hin, dass bei einer „[...] Analyse der Angstkonstruktionen [...] zwischen explizit benannter (dargestellter) und implizit mitkommunizierter (ausgedrückter) Angst [...]“ (ebd.) unterschieden werden müsse. Angst komme „[...] nicht nur wortbezogen, sondern [...] zwischen den Wörtern, Aussagen und Texten, durch die Art und Weise ihrer Kombination zustande.“ (ebd.)

7 Adrien Barbaresi, LukasBBAW, Vincent Barbaresi \& François Schmidts (2020): adbar/trafilatura: trafilatura-0.5.0 (Version v0.5.0). Zenodo. http://doi.org/10.5281/zenodo.3873402. 
steht darin, dass die Ausgabe als XML-Datei erfolgen kann, die neben einer Basisstruktur auch einige Metainformationen u. a. zu Autor, Datum und URL des jeweiligen Artikels enthält. Anschließend wurden die Artikel mit Hilfe des TreeTaggers (Schmid 1994 und 1995) getaggt. Der Wortform wurden auf diese Weise die Grundform bzw. das Lemma und die Wortart zugeordnet. Wird im Folgenden auf die Wortart Bezug genommen, so entspricht die Benennung dem STTS-Tagset. ${ }^{8}$

Anschließend wurde ausgehend vom Gesamtkorpus ein Spezialkorpus gebildet. Dabei wurden jene Artikel dem Spezialkorpus zugeordnet, die mindestens ein Lemma der Form ^Angst | angst $\${ }^{9}$ im Titel oder Volltext enthielten. Zumeist handelte es sich um das Lemma Angst, aber auch die Formen Angstgegner, Angststörung, Todesangst, Berührungsangst, Angstzustand, Existenzangst, Terrorangst, Abstiegsangst, Zukunftsangst, Höhenangst, Flugangst, Verlustangst, Urangst und Angstmacherei wurden neben weiteren durch das Suchmuster gefunden und als Entscheidungskriterium für die Artikelzuordnung genutzt. Auf diese Weise konnten 34.451 Artikel gefunden werden, die das Suchmuster enthalten. Diese bildeten das Spezialkorpus, dem im Rahmen der korpusvergleichenden Studie die verbliebenen Artikel aus dem Gesamtkorpus gegenübergestellt wurden. Die Tokenfrequenzen des Gesamt- und Spezialkorpus sind in Tab. 1 dargestellt.

Wie der Frequenzverlauf des Lexems Angst in Abbildung 1 (s. Anhang) verdeutlicht, ist das Lexem über den Untersuchungszeitraum hinweg i. d. R. mit einer relativen Frequenz von über 10,0 pro 100.000 Token belegt. Es gibt einzelne starke Ausschläge, bei denen sich die Frequenz nahezu verdoppelt. Ein Ausschlag tritt Ende des Jahres 2014 und Anfang des Jahres 2015 auf. Eine zu den Vorjahren vergleichsweise hohe Frequenz des Lexems bleibt von Ende 2015 bis Anfang 2018 hin bestehen. Danach flacht der Frequenzverlauf ab. Ein besonders starker Anstieg vollzieht sich wiederum im Monat März 2020, wobei die Tendenz in den nachfolgenden Monaten fallend ist. Sicherlich können diese Anstiege in der Frequenz des Lexems Angst mit verschiedenen Ereignissen wie der Flüchtlingskrise ab 2015 sowie der COVID-19-Pandemie in Verbindung gebracht werden.

8 Beispiele und Hinweise zum STTS-Tagset sind auf der entsprechenden Website der Universität Stuttgart abrufbar: https://www.ims.uni-stuttgart.de/forschung/ressourcen/lexika/germantagsets (zuletzt aufgerufen am 03.08.2020).

9 Bei den Suchmustern wurden reguläre Ausdrücke wie „^“ als ,Beginn der Zeichenkette“, „|“ als ,oder“ sowie „\$“ als ,Ende der Zeichenkette“ verwendet. 
Tab. 1: Anzahl der Token nach Jahren im Untersuchungskorpus

Gesamtkorpus ZEIT und SPIEGEL von 2013 bis 2020

\begin{tabular}{|c|c|c|c|c|c|}
\hline Jahr & Quelle & $\begin{array}{r}\text { Token nach Quel- } \\
\text { le } \\
\text { Gesamtkorpus }\end{array}$ & $\begin{array}{r}\text { Token nach } \\
\text { Quelle } \\
\text { Spezialkorpus }\end{array}$ & $\begin{array}{r}\text { Gesamtanzahl } \\
\text { Token } \\
\text { Gesamtkorpus }\end{array}$ & $\begin{array}{r}\text { Gesamtanzahl } \\
\text { Token } \\
\text { Spezialkorpus }\end{array}$ \\
\hline \multirow[t]{2}{*}{2013} & SPIEGEL & 22.733 .377 & 1.962 .679 & 50.036 .804 & 3.610 .275 \\
\hline & ZEIT & 27.303 .427 & 1.647 .596 & & \\
\hline \multirow[t]{2}{*}{2014} & SPIEGEL & 19.019 .258 & 1.827 .685 & 43.611 .898 & 3.792 .866 \\
\hline & ZEIT & 24.592 .640 & 1.965 .181 & & \\
\hline \multirow[t]{2}{*}{2015} & SPIEGEL & 17.275 .568 & 1.866 .158 & 38.168 .007 & 3.985 .444 \\
\hline & ZEIT & 20.892 .439 & 2.119 .286 & & \\
\hline \multirow[t]{2}{*}{2016} & SPIEGEL & 18.429 .495 & 2.637 .048 & 38.926 .599 & 5.233 .671 \\
\hline & ZEIT & 20.497 .104 & 2.596 .623 & & \\
\hline \multirow[t]{2}{*}{2017} & SPIEGEL & 19.479 .222 & 3.062 .212 & 34.560 .006 & 5.648 .445 \\
\hline & ZEIT & 15.080 .784 & 2.586 .233 & & \\
\hline \multirow[t]{2}{*}{2018} & SPIEGEL & 21.268 .636 & 2.925 .339 & 40.655 .278 & 5.944 .165 \\
\hline & ZEIT & 19.386 .642 & 3.018 .826 & & \\
\hline \multirow[t]{2}{*}{2019} & SPIEGEL & 19.921 .886 & 2.146 .504 & 47.656 .272 & 5.251 .307 \\
\hline & ZEIT & 27.734 .386 & 3.104 .803 & & \\
\hline \multirow[t]{2}{*}{2020} & SPIEGEL & 9.988 .355 & 1.850 .975 & 22.138 .657 & 3.643 .040 \\
\hline & ZEIT & 12.150 .302 & 1.792 .065 & & \\
\hline
\end{tabular}

So bieten diese Frequenzausschläge, die sich im Rahmen von explorativen Studien auch in den Jahren vor 2013 zeigten, einen guten Ausgangspunkt für themengeleitete diskurslinguistische Studien. So setzt sich beispielsweise Wengeler (2019) im Rahmen einer qualitativ-hermeneutischen Untersuchung mit argumentativen Mustern und metaphorischen Konzepten bezogen auf negative Zukunftshorizonte im Migrationsdiskurs seit 1970 auseinander.

\subsection{Ein datengeleiteter Angstwortschatz}

Im Rahmen der nachfolgenden Kollokationsanalyse soll untersucht werden, welche typischen Kontexte das semantische Feld des Lexems Angst prägen und wie sich das semantische Feld im diachronen Verlauf verändert. Somit stellt sich zunächst die Aufgabe, einen Angstwortschatz zusammenzustellen. So kann etwa auf den Deutschen Wortschatz nach Sachgruppen von Dornseiff (1959) 
zurückgegriffen werden. Unter der Hauptabteilung „11. Fühlen. Affekte. Charaktereigenschaften“ finden sich unter der Begriffsnummer „42. Furcht, Schrecken.“ (ebd.: 326) zahlreiche Wörter, die in semantischer Nähe zum Lexem Angst stehen. Darüber hinaus eignet sich GermaNet ${ }^{10}$ zur Bildung spezifischer Wortschätze. Hierbei handelt es um eine korpusgestützte lexikografische Datenbank. Lexikalische Einheiten mit gleicher Bedeutung sind in Synsets zusammenfasst, wobei GermaNet auch Informationen über die Relationen der Synsets enthält. ${ }^{11}$ Einen mit Hilfe von GermaNet zusammengestellten Angstwortschatz habe ich in Georgi (2018: 123) aufgeführt. Eine wesentliche Schwäche der beiden obigen Ressourcen liegt darin, dass diese statisch sind. Filatkina (2017) führt in diesem Zusammenhang aus, dass onomasiologische Wörterbücher und Ontologien wie GermaNet zwar Orientierungspunkte für einen Angstwortschatz bieten, jedoch den tatsächlichen Sprachgebrauch nicht abbilden können, da sich das semantische Feld der Angst, wie Filatkina (2015) bereits zeigen konnte, fortwährend ändert. Diese Problematik gab den Anstoß zur Erprobung einer dritten Möglichkeit des Wortschatzaufbaus, die auch die Veränderung des semantischen Feldes über die Zeit hinweg berücksichtigt. Der Ansatz basiert auf der Berechnung von Word Embeddings nach Mikolov et al. (2013). Auf der Basis ihrer Kontexte werden Wörter in Vektoren überführt. Bubenhofer, Calleri und Dreesen (2019: 224) zufolge kann davon ausgegangen werden, dass sich Wörter mit sehr ähnlichen Vektoren ,im gleichen semantischen Feld (bewegen)“ (ebd.). Bei den semantisch ähnlichsten Wörtern, den sogenannten Nearest Neighbours (NNs), handelt es sich nicht ausschließlich um Synonyme. So können auch „Antonyme, Hyperonyme und Hyponyme“ (ebd.) belegt sein. Bubenhofer, Calleri und Dreesen verstehen die Relationen zwischen den Nearest Neighbours als ,semantisch-funktionale Äquivalenzen in einem spezifischen Geltungsbereich“ (ebd.: 226): „NNs bilden ein diskursives Paradigma, da die mittels ihrer Position zueinander bestimmte semantischfunktionale Äquivalenz als eine Klasse von untereinander annähernd austauschbaren Zeichen aufgefasst werden kann.“ (ebd.)

Um die NNs zum Lexem Angst zu berechnen, wurde die Python-Bibliothek Gensim (Řehůřek/Sojka 2010) verwendet. ${ }^{12}$ Das Word2Vec-Model wurde mit

10 Online verfügbar unter: https://uni-tuebingen.de/en/142806 (zuletzt aufgerufen am 20.07.2020).

11 Für eine genauere Beschreibung der lexikalischen und konzeptuellen Relationen siehe: https://uni-tuebingen.de/en/142846 (zuletzt aufgerufen am 20.07.2020).

12 In diesem Zusammenhang danke ich Simon Meier-Vieracker herzlich für die PythonSkripte, die das Training des Word2Vec-Models und die Ausgabe der NNs ermöglichten. 
einer Fenstergröße von 10 einmal für das Gesamtkorpus und einmal ausschließlich für das Jahr 2020 trainiert. Anschließend erfolgte die Ausgabe der 100 ähnlichsten Wörter, also der NNs, zum Lexem Angst. Da die Berechnung auf der Basis der Wortformen erfolgte, kamen unter den NNs einige Wörter mehrmals in verschiedenen Flexionsformen vor. Diese wurden ebenso wie die übrigen Wortformen auf ihre Grundform zurückgeführt, sodass der in Tabelle 2 dargestellte Angstwortschatz weniger als 100 Lemmata umfasst. Neben dem unter [1] aufgeführten NNs-Angstwortschatz, der für das Gesamtkorpus berechnet wurde, sind unter [2] die einzigartigen Begriffe aufgerührt, die lediglich im Angstwortschatz auftreten, der für das Jahr 2020 berechnet wurde.

Tab. 2: NNs-Angstwortschatz [1] über das Gesamtkorpus 2013-2020 und [2] ausschließlich für das Jahr 2020, wobei lediglich die für 2020 einzigartigen Begriffe dargestellt sind ${ }^{13}$

[1] Furcht, Scheu, Sorge|Sorgen, Ehrfurcht, Wut, Existenzangst, warnen, Verzweiflung, Panik, Feigheit, Abscheu, Urangst, Berührungsangst, Auge, Heidenangst, Todesangst, Hochachtung, Schiss, Milchsee, Warnung, bewahren, fliehen, Frustration, Scham, Verbeugung, Bammel, Respekt, Haustür, kapitulieren, gaukeln, Gleichgültigkeit, alle, Langeweile, Verelendung, Rührung, Nachteil, Grundangst, Hysterie, Überfremdung, Tüllkleid, Perspektivlosigkeit, Hilflosigkeit, Verbitterung, Verneigung, Zukunftsangst, Lethargie, Schuldgefühl, Freude, Nervosität, Resignation, Ergriffenheit, Ignoranz, lauter, Gefühl, Vereinzelung, Phobie, Skrupel, Sorglosigkeit, Lust, Hass, Ekel, Überzuckerung, Schmerz, Wanderprediger, Riesenangst, zurückschrecken, Apathie, Mitleid, feien, Erschöpfung, Asozialität, Überforderung, schützen, bersten, Unzufriedenheit, Verachtung, Ressentiment, Hoffnungslosigkeit, Schwellenangst, Desillusionierung, Verbeugung, Panikmache, Schmerz, Fremde, Nase, Butterberg, Warnung, erblassen, Verlockung, Vorurteil, Springermedien, Bewegungsunfähigkeit

[2] Laus, Halt, Gefahr, Fäulnis, Hunger, Einnässen, Ohnmacht, Versorgungsengpass, Jugendstrafkammer, Tür, zurückweichen, Stigmatisierung, schlagen, fürchten, Ort, Saisonschlussphase, Machtwahn, Erschütterung, Sondereinflüsse, herausreißen, Gewiss-

13 Einige Begriffe erscheinen auf den ersten Blick widersprüchlich, da sie nicht synonym zu Angst sind. Das Lexem Tüllkleid ist im NNs Wortschatz in der Wortform Tüllkleidern belegt. Die Korpusbelege zeigen, dass der Wortform eine Präposition vorangeht, sodass eine strukturelle Ähnlichkeit zu Präpositionalphrasen wie „aus Angst“ oder „in Angst“ besteht. Ähnlich verhält es sich mit dem Lexem Laus, das im Dativ Plural Läusen im Wortschatz belegt ist. Der Wortform Zinsabrede folgt in einem Beleg etwa eine Präposition, sodass eine Ähnlichkeit zu Angst vor besteht. So ist ergänzend zu Bubenhofer, Calleri und Dreesen (2019) hinzuzufügen, dass unter den NNs unter Umständen auch strukturelle Äquivalenzen ohne semantischen Bezug zu finden sind. Diese eröffnen wiederum Einsichten über charakteristische strukturelle Verbindungen des Ausgangslexems. 
heit, Einsamkeit, Unzuverlässigkeit, stakkatohaft, geborgen, grob, Ansteckung, Bedrohung, flüchten, Aussichtslosigkeit, Trauer, Vorrang, haltmachen, Verletzungsproblem, Rassismuserfahrung, Besorgnis, Unwissenheit, Erfrieren, Vornahme, ungeschützt, Gewohnheit, Unruhe, Personenwahl, Erbrechen, Coronaausbruch, Befürchtung, grauen, preschen, furchtsam, Panikattacke, Zinsabrede, plötzlich, zurückzucken, strotzen

Im Wortschatz für das Gesamtkorpus sind Begriffe enthalten, die nahezu Synonyme des Lexems Angst sind, wie Furcht, Sorge/Sorgen, Panik, Feigheit und Bammel. Ferner sind weitere Gefühlsbezeichnungen enthalten, wie Wut, Langeweile, Frustration, Scham, Lust, Hass und Ekel. Außerdem finden sich verschiedene Komposita: Existenzangst, Berührungsangst, Heidenangst, Todesangst, Grundangst, Zukunftsangst und Riesenangst. Weiterhin sind mit Sorglosigkeit, Apathie und Gleichgültigkeit potentielle Antonyme vertreten. Interessanterweise sind die beiden Teile des niedrig frequenten Phraseologismus Milchseen und Butterberge enthalten. Dieser verweist metaphorisch auf eine Überproduktion in der Landwirtschaft, die zu Einkommenseinbußen der Bäuerinnen und Bauern führen und somit existentielle Ängste hervorrufen kann. Somit steht der Ausdruck Milchseen und Butterberge metaphorisch für die Überproduktion als eine mögliche Ursache für Angst. Vielmehr gehe ich jedoch davon aus, dass die beiden Lexeme des Phraseologismus aufgrund ihrer strukturellen Ähnlichkeit zum Lexem Angst als NNs erscheinen. So tritt auch Angst, wie die nachfolgenden Studien zeigen werden und wie mit Bezug auf Holzinger (2018) bereits verdeutlicht wurde, vermehrt innerhalb von Paarformeln auf, beispielsweise in der Form Angst und Schrecken. Bei den Verben sind v. a. solche belegt, die eine Reaktion auf etwas ausdrücken, wie fliehen, kapitulieren, zurückschrecken und erblassen. Bei den Unterschieden des Angstwortschatzes für das Jahr 2020 im Vergleich zu jenem des Gesamtkorpus lassen sich zeittypische Lexeme identifizieren, die wie Versorgungsengpass, Einsamkeit, Ansteckung, ungeschützt und Coronaausbruch auf die COVID-19-Pandemie und mit Rassismuserfahrung auf die weltweiten Proteste gegen Polizeigewalt und Rassismus in Folge des Todes von George Floyd Ende Mai 2020 verweisen. Bei den genannten Begriffen für das Jahr 2020 handelt es sich vorrangig um Ursachen und Gegenstände der Angst.

Um die Unterschiede im semantischen Feld zwischen dem GermaNet- und NNs-Wortschatz überprüfen zu können, wurden zunächst die Kollokationen der Lexeme des jeweiligen Wortschatzes im Gesamtkorpus für das Jahr 2020 be- 
rechnet und anschließend in Rhizomen visualisiert. ${ }^{14}$ Diesen Netzwerkstrukturen liegt, basierend auf den Signifikanzwerten der Kollokatoren, ein force-based Algorithmus zugrunde, den Scharloth, Eugster und Bubenhofer (2013) in folgender Weise beschreiben: „Der Algorithmus sorgt [...] dafür, dass zwei oder mehr Knoten, die mit einer gleichen oder sehr ähnlichen Menge anderer Knoten verbunden sind, in relativer Nähe zueinander dargestellt werden. Verdichtungsbereiche im Graphen lassen also auf eine Gruppe von Knoten mit ähnlichen Vernetzungsmerkmalen schließen.“ (ebd.: 366) Bevor im nachfolgenden Kapitel 4.4 genauer auf die Ergebnisse der Kollokationsanalyse eingegangen wird, erfolgt der Vergleich der beiden Wortschätze zunächst ausschließlich auf der Basis der Visualisierungen als grundlegende „[...] Mittel der Erkenntnisgewinnung, wenn andere Formen der Repräsentation wie Listen, Tabellen oder Texte zu umfangreich oder zu komplex sind, um als Ganze erfasst und interpretiert werden zu können." (Scharloth/Eugster/Bubenhofer 2013: 363) Betrachtet man die in den Abbildungen 2.1 und 2.2 (s. Anhang) dargestellten Rhizome, wird deutlich, dass die Knoten des NNs-Angstwortschatzes deutlich dichter beieinanderstehen als jene des GermaNet-Angstwortschatzes. Außerdem finden sich beim NNs-Angstwortschatz deutlich weniger Knoten, die weitgehend unverbunden in der Peripherie erscheinen. Insgesamt verdeutlichen die Rhizome, dass im Falle des NNs-Angstwortschatzes die Begriffe sehr ähnliche Kollokationsprofile aufweisen und demzufolge als Knoten weitgehend verbunden und nah beieinander erscheinen. Der Word Embeddings-Ansatz erweist sich somit als sehr geeignet, um das semantische Feld von Lexemen zu erkunden. Gegenüber Wörterbüchern und Ontologien ist dieser Ansatz weniger statisch, da das semantische Feld datengeleitet auf der Basis verschiedenster Korpora berechnet werden kann und somit auch zeitlich bedingte Veränderungen im semantischen Feld berücksichtigt werden können. Allerdings bedarf es für Schlussfolgerungen hinsichtlich der Gebrauchssemantik eines Lexems, wie Bubenhofer, Calleri und Dreesen (2019: 227) bereits ausführen, der Deutung der NNs auf der Basis von Kollokationen und Textbelegen. Diese soll im Folgenden anhand ausgewählter Beispiele erfolgen.

14 An dieser Stelle bedanke ich mich herzlich bei Joachim Scharloth, der mir mehrere PerlModule zur Berechnung und Visualisierung von Kollokationen bereitgestellt hat, die ich auf die vorliegende Untersuchung hin leicht angepasst habe. 


\subsection{Kollokationsanalyse}

Auf der Basis des NNs-Angstwortschatzes, der für das Gesamtkorpus bestimmt wurde, wurden die Kollokationen für die Jahre 2019 und 2020 berechnet, wobei das Kontextfenster jeweils 10 Wörter rechts und links von der Basis betrug. Anschließend wurden die Kollokationen wiederum in Rhizomen visualisiert. Ausschnitte aus diesen Rhizomen mit dem Fokus auf den unmittelbaren Kollokaten des Lexems Angst sind in den Abbildungen 3 (für das Jahr 2019) und 4 (für das Jahr 2020) dargestellt (dazu s. Anhang).

Für das Jahr 2019 lässt sich auf der Basis des Rhizoms feststellen, dass Angst häufig verbunden mit anderen Gefühlsbezeichnungen wie Wut, Panik, Überforderung, Furcht, Sorge/Sorgen, Hysterie, Unsicherheit, Ekel, Hass, Scham und Schrecken erscheint. Die höchsten Signifikanzwerte sind dabei für Schrecken, Wut und Hass belegt. Das Lexem Angst erscheint, wie Holzinger (2018: 236-238) in Bezug auf die Präpositionalphrase mit Angst ... bereits festgestellt hat, häufig in Paarformeln mit den übrigen Gefühlsbezeichnungen. Neben der Verbindung durch die Konjunktion und, die die häufigste Form der Verknüpfung darstellt, ist beispielsweise die Verknüpfung durch wie belegt, wie das folgende Beispiel (1) illustriert. Über das vorangestellte Attribut werden Angst und Wut Greta Thunberg infolge ihrer emotionalen Rede - geprägt durch die wiederholte Frage How dare you? - beim Klimagipfel der UN Ende September 2019 zugeschrieben.

(1) In New York hatte auch Angela Merkel die Klimabewegung der jungen Leute gelobt, so wie Greta Thunberg persönlich bei den UN förmlich zugelobt wurde, bis sie ihren irritierenden Wutanfall bekam und eine Rede hielt, wie man sie von ihr noch nicht kannte, so, als wolle sie sich durch Aggression vor all dem tatenarmen Schulterklopfen schützen. Was im Falle der nach ihr auftretenden Kanzlerin nicht recht half, denn die überhörte Gretas Angst wie Gretas Wut und sagte unbeeindruckt: „Wir alle haben den Weckruf der Jugend gehört.“ (DIE ZEIT, 25.09.2019) ${ }^{15}$

Ferner gibt es Aufzählungen, die z.T. mehr als zwei Gefühlsbezeichnungen enthalten, und auf diese Weise ein Stimmungsbild aus verschiedenen Emotionen erzeugen. In Beispiel (2) wird auf die Stimmung in Großbritannien in Folge der Debatte um den Brexit Bezug genommen. Verunsicherung, Angst und Wut

15 Bei den Zitaten handelt es sich um Textausschnitte aus verschiedenen Artikeln der ZEIT und des SPIEGELS. Dabei sind sowohl die Print- als auch die Online-Versionen eingeschlossen. Sofern nicht anders angegeben, erfolgen die Hervorhebungen durch mich. 
werden als Resultat von fehlendem Vertrauen den vielen Bürgern als einem weitgehend unbestimmten Teil der Bevölkerung Großbritanniens zugeschrieben und als wachsend charakterisiert.

(2) In der Soziologie gilt Vertrauen als die Grundlage aller sozialen Beziehungen. Es ist eine der entscheidenden Voraussetzungen für das friedliche Zusammenleben in einer Gesellschaft. Fehlt es daran, wachsen Verunsicherung, Angst und Wut. Viele Bürger haben das Gefühl, nichts mehr glauben zu können - nicht den Medien, nicht der Justiz oder dem gesamten staatlichen System. (DIE ZEIT, 13.03.2019)

Grundsätzlich ist zu bemerken, dass die additiven Reihungen der Gefühlsbezeichnungen Schlussfolgerungen dahingehend erschweren, ob die Emotionen schlicht nebeneinander existieren oder etwa auseinander resultieren. Kausalität wird in der Regel nicht eindeutig ausgedrückt. Beispiel (3) bildet somit eine Ausnahme. Angst vor explodierenden Mieten wird hier als Ursache für die Wut in New York und bei Washington angenommen. Die Städte stehen dabei metonymisch für deren Bürgerinnen und Bürger, denen diese beiden Emotionen zugeschrieben werden.

(3) Mit den Zehntausenden gut bezahlter IT-Experten stiegen aber auch die Mieten, zugleich gibt es immer mehr Obdachlose. Nachdem Amazon im Herbst ankündigte, in New York und bei Washington neue Konzernzentralen zu eröffnen, war auch dort die Wut aus Angst vor explodierenden Mieten riesig. (DER SPIEGEL, 17.01.2019)

Neben den Gefühlsbezeichnungen treten einige Adjektive signifikant häufig zusammen mit dem Lexem Angst auf: groß, deutsch und irrational. Aus der Sichtung der Key Words in Context (KWIC) ergibt sich, dass deutsch zumeist nicht als attributives Adjektiv des Lexems Angst gebracht wird, sondern sich wie in Beispiel (4) auf ein weiteres Nomen bezieht. Beispiel (5) stellt somit einen Sonderfall dar, bei dem die Angst vor dem Neuen, dem Unbekannten als groß und deutsch charakterisiert wird. Der Träger, auf den sich diese Angst bezieht, wird nicht explizit genannt. Aus dem Kontext lässt sich schließen, dass es sich um die Mitglieder des Bundestags handelt, wobei unbestimmt bleibt, ob eine Einschränkung auf bestimmte Parteien oder Zeiträume erfolgt.

(4) Denn nicht nur bei den erfolgreichen deutschen Autoexporteuren hatte in den vergangenen Monaten die Angst ums Geschäft grassiert, auch in den 
USA schlug die Sorge vor den Folgen möglicher Importbeschränkungen des US-Präsidenten hoch. (DER SPIEGEL, 16.05.2019)

(5) So ist es 14 Jahre lang geblieben. Niemand hat sich getraut, nicht einmal in der Zeit, als SPD, Grüne und Linke eine Mehrheit im Bundestag hatten. Dahinter steht auch die große deutsche Angst vor dem Neuen, dem Unbekannten. Hält sich jemand für eine Weile im Kanzleramt, kann er meist bleiben, wenn er nicht die Nerven verliert wie Willy Brandt oder Gerhard Schröder. Merkel hat nie die Nerven verloren, und das spricht natürlich für sie. (DER SPIEGEL, 07.12.2019, Herv. im Original)

Das Adjektiv irrational ist hingegen sowohl als attributives Adjektiv zum Lexem Angst wie in Beispiel (6) als auch als Prädikativum wie in Beispiel (7) belegt. Beide Beispiele deuten auf einen spezifischen Diskurs zur Angemessenheit bzw. Unangemessenheit von Angst hin. In Beispiel (6) wird das Problem angesprochen, dass von der Zugehörigkeit zu einer Ethnie auf kriminelles Verhalten geschlossen wird. Ängste, die aus dieser Schlussfolgerung resultieren, werden als irrational und panik-geneigt charakterisiert. Somit wird ausgedrückt, dass kein rationaler Gegenstand der Angst vorliegt. Als Träger der Angst wird die Mehrheitsbevölkerung genannt, wobei es sich wiederum um ein Kollektiv mit unbestimmten Grenzen handelt. Darüber hinaus wird die Angst vor dem Verlust von Wählerinnen und Wählern selbst als irrationaler Beweggrund charakterisiert.

(6) Es führt zu einer Verzerrung der Wahrnehmung bis hin zu irrationalen, panik-geneigten Ängsten der Mehrheitsbevölkerung. Wie leicht sich diese mobilisieren lassen, zeigte sich zuletzt in der Debatte über ein[e] mutmaßliche Sexualstraftat von mehreren Kindern und Jugendlichen geringen Alters (12 bis 14 Jahre) in Mülheim im Sommer 2019, weil die möglichen Täter aus Familien bulgarischer Roma stammen, von denen eine große Zahl vor allem in Duisburg [...] wohnt. (DER SPIEGEL, 07.11.2019, Ergänzung durch C.G.)

(7) Dass die Grünen sich trauen, darüber hinaus aber auch für ordnungspolitische Maßnahmen zu werben, ist dennoch richtig. Denn auch wenn diese für einen wirksamen Klimaschutz nur ein Element sind, das nur eingesetzt werden sollte, wenn es keine bessere Möglichkeit gibt: Aus Angst vor Wählerinnen und Wählern darauf zu verzichten, wäre irrational. (DIE ZEIT, 17.11.2019) 
In den vorangegangenen Beispielen ist bereits deutlich geworden, dass häufig Kollektivbezeichnungen als Träger der Angst genannt werden, die insgesamt vage bleiben und somit die Feststellung Filatkinas (2015) stützen. In den Kollokationen ist dies im Lemma Mensch belegt, wobei dieses häufig im Plural Menschen erscheint. Mit Fremde, US-Strafen, Jobverlust und Überfremdung erscheinen typische Gegenstände der Angst unter den Kollokationen, wobei die Anzahl der Belege im Korpus relativ gering ist.

Interessant ist schließlich das Lexem Prozent als Kollokator von Angst. Filatkina (2015: 105) hat bereits im Kontext des Begriffs Zukunftsangst Verweise auf Studien zur Angst der Deutschen festgestellt, die den apodiktischen Charakter des Lexems unterstützen. Im folgenden Beispiel (8) werden die Ergebnisse der Shell-Jugendstudie wiedergegeben, wobei der Anteil der größten Ängste der Befragten vor Umweltverschmutzung, Terroranschlägen und dem Klimawandel in Prozent wiedergegeben wird. Ausführungen dieser Art erschweren es, die thematisierte Angst anzuzweifeln. Filatkina zufolge betonen sie die Allgegenwärtigkeit der Angst. Außerdem erzeugen sie die Vorstellung, dass sich die Gegenstände der Ängste der Befragten über die Zeit hinweg verändern, wobei stets bestimmte Gegenstände in der Gesellschaft oder in Teilen der Gesellschaft überwiegen.

(8) Laut einer Umfrage ist Umweltverschmutzung das beherrschende Thema, wenn es um die Zukunftsängste junger Menschen in Deutschland geht. 71 Prozent der 12- bis 25-Jährigen gaben in einer Befragung an, das Thema mache ihnen Angst, so das Ergebnis der in Berlin veröffentlichten ShellJugendstudie. In der vergangenen Studie aus dem Jahr 2015 hatte noch die Angst vor Terroranschlägen vorn gelegen. Dieses Thema ängstigt nach der jüngsten Befragung heute noch zwei Drittel der jungen Menschen. Die Angst vor dem Klimawandel landet auf Platz drei (65 Prozent). (DIE ZEIT, 15.10.2019)

Im Jahr 2020 ist Angst wiederum mit Gefühlszuständen verbunden, wobei andere Gefühlsbezeichnungen in die Nähe des Lexems rücken, wie Nervosität, Langeweile, Depression, Hilflosigkeit, Phobie, Stress und Trauer. Häufig sind, wie sich für das Jahr 2019 bereits gezeigt hat, gleich mehrere Gefühlszustände durch Aufzählungen miteinander verbunden. In Beispiel (9) wird Angst zusammen mit Langeweile, Wut und Depression als Stimmungsbild aufgezählt. Dabei ist dieses Stimmungsbild in die Zukunft gerichtet, als mögliche Konsequenz der anhaltenden gesellschaftlichen Beschränkungen zur Eindämmung des Coronavirus, deren Ende im März sowie Anfang April 2020 noch nicht absehbar war. Zugleich 
wird dieses Stimmungsbild als mögliche Ursache für eine Verkapselung oder einen offenen Widerstand der Menschen genannt.

(9) Niemand kann seriös beurteilen, ob die Feinde der Demokratie nicht irgendwann noch mehr Aufwind bekommen als sie es ohnehin schon hatten.

Ob Langweile, Wut, Depression oder Angst die Menschen nicht tatsächlich in die stille Verkapselung oder in offenen Widerstand treibt. (DIE ZEIT, 30.03.2020)

Wiederum werden Studien herangezogen, um die Kausalität zwischen dem Corona-Ausbruch und einer gestiegenen Rate an Depressionen und Angst zu stützen, wie Beispiel (10) illustriert:

(10) Daten aus China weisen darauf hin, dass die Rate an Depressionen, Angst und Schlafproblemen seit dem Corona-Ausbruch in dem Land gestiegen ist. (DER SPIEGEL, 15.04.2020)

Darüber hinaus wird Angst mit semantisch ähnlichen Gefühlszuständen gleichgesetzt, wie Beispiel (11) verdeutlicht:

(11) Da eine Langeweile in Nervosität - in der steten Angst vor dem Virus und seinen Folgen - lähmt, müssen wir sie gewissermaßen umpolen, sie wider alle Intuition und Skepsis bejahen und gerade in ihrem vermeintlichen Nichts den Sinn suchen. (DIE ZEIT, 28.03.2020)

Die stete Angst vor dem Virus und seinen Folgen wird in diesem essayistischen Artikel zum Phänomen der Langeweile mit Nervosität gleichgesetzt. Dabei wird Angst in Verbindung mit Langeweile eine lähmende Wirkung zugeschrieben, die - so die programmatische Aussage des Artikels - zu beseitigen sei, indem die Langeweile umzupolen und $\mathrm{zu}$ bejahen, also gewissermaßen als konstruktiv $\mathrm{zu}$ betrachten sei. Somit zeigt sich ein weiteres Mal ein spezifischer Diskurs zur Angemessenheit der Angst, wobei diese als unangemessen bzw. mit negativen Effekten einhergehend gekennzeichnet wird.

Die Adjektive zur näheren Charakterisierung der Angst wie groß und irrational bleiben auch im Jahr 2020 als Kollokate bestehen. Als attributives Adjektiv verweist groß auf einen gesteigerten Grad der Angst. Darüber hinaus tritt groß in seinen Steigerungsformen gemeinsam mit Angst auf. Auf diese Weise wird deutlich, dass zum einen zwischen verschiedenen Ängsten unterschiedlich hoher Intensität unterschieden wird - wie auch die bereits zitierten Ausführungen zu 
Angststudien nahelegen - und zum anderen die Intensität der Angst, bezogen auf bestimmte Gegenstände, als zeitlich dynamisch gekennzeichnet wird, wie Beispiel (12) verdeutlicht, das die Aussagen des Psychologen Steven Taylor wiedergibt:

(12) Wir wissen aber auch, dass gerade zu Beginn einer Pandemie die Angst am größten ist. Sie nimmt im Laufe des Ausbruchs meist ab, wenn sich eine neue Normalität einstellt. (DIE ZEIT, 16.03.2020)

Das Adjektiv irrational verweist wiederum auf den Diskurs zur Angemessenheit von Angst in Bezug auf verschiedene Gegenstände, der dem Beispiel (13) zufolge zwischen den Polen irrational und rational verläuft. Die Äußerung stammt von der stellvertretenden Vorsitzenden des Deutschen Ethikrates, Claudia Wiesemann, in Bezug auf die Widerspruchsregelung bei Organspenden, über die Mitte Januar 2020 im Bundestag entschieden wurde. Den irrationalen Ängsten vor Organspenden, die angeblich auf Nicht-Wissen zurückzuführen seien, wird die rationale Angst vor dem Sterben gegenübergestellt, die in diesem Kontext ebenfalls $\mathrm{zu}$ berücksichtigen ist.

(13) Angeblich wissen die Menschen nicht genug über Organspenden und entscheiden sich deshalb nicht. Also fließt Geld in Aufklärungskampagnen, damit wir unsere Bequemlichkeit und irrationalen Ängste aufgeben. Dabei ist es kein bisschen irrational, Angst vorm Sterben zu haben. (DER SPIEGEL, 15.01.2020)

Schließlich erscheint es wenig verwunderlich, dass als weitere Kollokate neue Gegenstände der Angst wie Coronavirus, Virus und Ansteckung erscheinen. So ist die Angst vor dem Virus und seinen Folgen (vgl. Beispiel (11)) im Rahmen der Corona-Pandemie sehr häufig thematisiert worden. Dies lässt sich quantitativ anhand der Realisierungsformen des Musters „Angst vor NN|NE“ belegen. Wie in Kapitel 3 bereits dargelegt wurde, verweisen Präpositionalphrasen mit vor nach Filatkina auf die Gegenstände der Angst. Vergleicht man die verschiedenen Realisierungsformen des Musters in den Jahren 2014, 2016, 2018 und 2020, wie sie in Tabelle 3 dargestellt sind, wird deutlich, dass Ansteckung und Corona als Gegenstände der Angst die insgesamt höchste relative Frequenz aufweisen. Zugleich wird ersichtlich, dass sich angstauslösende Ereignisse wie die Ebolafieber-Epidemie in Westafrika im Jahr 2014 oder wiederkehrende Terroranschläge auf die zentralen Gegenstände der Angst auswirken oder selbst als zentrale Gegenstände erscheinen. Die Aufstellung in Tab. 3 lässt zugleich eine zeitliche 
Dynamik erahnen. So ist das Lexem Ebola nur für das Jahr 2014 als zentraler Gegenstand der Angst belegt (2015 und 2016 erscheint das Lexem ebenfalls, allerdings in einer sehr niedrigen Frequenz von 0,005 bzw. 0,003). Kontinuierlich über mehrere Jahre hinweg erscheinen die Lexeme Anschlag, Überfremdung, Flüchtling, Veränderung sowie Repressalie/Repression. Somit wäre es interessant zu prüfen, welche Lexeme über einen bestimmten Zeitraum hinweg konstant als Gegenstände der Angst erscheinen und welche Lexeme in den einzelnen Jahren neu als Gegenstände hinzutreten, wie es etwa bei Corona der Fall ist. Für das Jahr 2019 sind immerhin 292 verschiedene Gegenstände der Angst im Rahmen der Präpositionalphrase im vorliegenden Korpus realisiert, für 2020 sind es 161. ${ }^{16}$ Da es den Rahmen des vorliegenden Beitrages übersteigen würde, sei an dieser Stelle lediglich auf diesen Untersuchungsansatz verwiesen.

Tab. 3: Realisierungsformen des Suchmusters „Angst vor NN|NE“ im Gesamtkorpus nach Jahren mit relativer Frequenz pro 100.000 Token

\begin{tabular}{|c|c|c|c|c|c|c|c|}
\hline 2014 & & 2016 & & 2018 & & 2020 & \\
\hline Ebola & 0,080 & Überfremdung & 0,064 & Übergriff & 0,027 & Ansteckung & 0,294 \\
\hline Anschlag & 0,048 & Terror & 0,062 & Repressalie & 0,025 & Corona & 0,099 \\
\hline IS-Massaker & 0,032 & Flüchtling & 0,054 & Konsequenz & 0,025 & Infektion & 0,041 \\
\hline Entdeckung & 0,025 & Anschlag & 0,054 & Fremde & 0,025 & Jobverlust & 0,027 \\
\hline Veränderung & 0,023 & Terroranschlag & 0,041 & Überfremdung & 0,025 & Kontrollverlust & 0,027 \\
\hline Repressalie & 0,021 & Veränderung & 0,039 & Flüchtling & 0,022 & Repression & 0,023 \\
\hline
\end{tabular}

Insgesamt haben die Untersuchungen $\mathrm{zu}$ den Kollokaten der Angst ergeben, dass das Lexem häufig in Paarformeln und Aufzählungen verschiedener Gefühlszustände erscheint. Über die Adjektive irrational und rational ist zudem ein spezifischer Diskurs zur Angemessenheit bzw. Unangemessenheit der Angst in Bezug auf spezifische Gegenstände belegt. Als Träger der Angst erscheinen häufig Kollektive, die bezüglich ihrer Zusammensetzung vage bleiben. Darüber hinaus sind über den Kollokator Prozent zahlreiche Verweise auf Studien im Zusammenhang mit Angst belegt. Schließlich wird Angst mit Hilfe des Adjektivs

16 Selbstverständlich dienen weitere morphosyntaktische und syntaktische Strukturen dazu, Gegenstände der Angst zu thematisieren, beispielsweise dass-Sätze, die auf das Lexem folgen wie die Untersuchungen zu den n-Grammen noch belegen werden. Somit sollten weitere Strukturen im Rahmen der Untersuchung der Gegenstände der Angst Berücksichtigung finden. 
gro $\beta$ in seinen verschiedenen Steigerungsformen als dynamisch in Bezug auf verschiedene Gegenstände und Zeiträume gekennzeichnet.

\subsection{Signifikante $n-G r a m m e$}

Wie bereits in Kapitel 4.1 dargelegt wurde, sollte eine Analyse der Angstkonstruktionen nicht ausschließlich ausgehend vom explizit thematisierten Lexem Angst erfolgen. Ebenso wichtig sind Kontexte, in denen Angst implizit zum Ausdruck gebracht wird. Im Folgenden sollen eben jene Kontexte neben den expliziten Formen auf typische Wortverbindungen hin überprüft werden. Dabei gehe ich grundlegend von der Annahme aus, dass ein Artikel, der das Lexem Angst in der Überschrift oder im Volltext enthält, ebenfalls Formen der impliziten Thematisierung aufweist und dass diese musterhaft sind. Um jene musterhaften Verbindungen, die auf Angstkonstruktionen hinweisen, ermitteln zu können, wurden signifikante komplexe und Lemma-n-Gramme berechnet. Dabei ist das Lexem Angst nur in einem Teil der n-Gramme belegt.

Grundlegend ist unter Wort-n-Grammen eine Kette unmittelbar aufeinander folgender Wörter der Länge $n \mathrm{zu}$ verstehen, im Sinne: Wort-1-Wort-2-Wort-3Wort-4-Wort-n (vgl. Bubenhofer 2017: 73f.). Die Länge der n-Gramme beträgt in der vorliegenden Untersuchung vier. Da ich die Grundform der Wörter bei der Bildung der n-Gramme berücksichtigt habe, verwende ich den Ausdruck Lemma-n-Gramm. Bei den komplexen n-Grammen wurden sämtliche Funktionswörter, also Artikel, Konjunktionen, Partikeln, Pronomen, Präpositionen, Modalverben und Hilfsverben, sowie Zahlausdrücke durch die Wortarten ersetzt. Auf diese Weise können verschiedene Realisierungsformen eines auf der Inhaltsebene grundsätzlich ähnlichen Musters als komplexes n-Gramm zusammengefasst werden. Zur Deutung des komplexen n-Gramms können schließlich die Realisierungsformen hinzugezogen werden, wie Bubenhofer (2017: 82f.) exemplarisch verdeutlicht.

Zunächst wurde das Spezialkorpus, das die Artikel mit dem Lexem Angst in der Überschrift oder im Volltext enthielt, über den gesamten Untersuchungszeitraum hinweg mit dem Vergleichskorpus, das die übrigen Artikel ohne das Lexem Angst enthielt, verglichen. Dabei wurden jene komplexe n-Gramme ermittelt, die im Spezialkorpus signifikant häufiger auftreten als im Vergleichskorpus. Im folgenden Unterkapitel werden die Ergebnisse wiedergegeben. Anschließend wurde das Spezialkorpus in zwei Teilkorpora unterteilt. Ein Korpus umfasste das Jahr 2020, während das andere Korpus die Artikel aus den übrigen Jahren 2013 bis 2019 enthielt. Im Vergleich beider Korpora wurden jene Lemman-Gramme ermittelt, die im Jahr 2020 signifikant häufiger auftreten als in den 
vergangenen Jahren. Die Ergebnisse dieser Studie werden in Kapitel 4.5.2 wiedergegeben. In beiden Untersuchungen wurde der Log-Likelihood-Test (im Folgenden für die resultierenden Werte bezugnehmend auf die englische Bezeichnung „Log-Likelihood Ratio“ als LLR abgekürzt) verwendet, um zu prüfen, ob der Unterschied in der relativen Frequenz eines $n$-Gramms in den beiden Korpora signifikant ist (entspricht einem p-Wert von <0,05).

Für beide Berechnungen ergaben sich sehr umfangreiche Listen von nGrammen mit dem zugehörigen Signifikanzwert, die schwer zu überblicken sind. Durch die Anwendung eines Clustering-Algorithmus konnten ähnliche nGramme zu Gruppen zusammengefasst werden. Dabei habe ich mich an Bubenhofer (2017: 76) orientiert und die Daten, wie von Bubenhofer beschrieben, vorbereitet. Zusätzlich habe ich alle n-Gramme entfernt, deren LLR-Wert kleiner oder gleich 60 betrug. Bei den komplexen n-Grammen wurden auf diese Weise von 175.625 signifikanten n-Grammen lediglich 1268 n-Gramme für das Clustering berücksichtigt. Das Clustering erfolgte auf der Basis einer hierarchischen agglomerativen Clusteranalyse, die nach Gries (2013: 336-349) in $\mathrm{R}^{17}$ implementiert wurde, wobei die Distanzmatrix basierend auf der Euklidischen Distanz berechnet wurde und die Clusterbildung nach der Ward-Methode erfolgte. Die Anzahl der Gruppen, zu denen die n-Gramme zusammengefasst werden, ist für die Ausgabe grundsätzlich manuell festzulegen. Für die Lemma-n-Gramme erwiesen sich 30 Gruppen, für die komplexen n-Gramme 19 Gruppen als geeignet. In Abbildung 5 (s. Anhang) sind letztere innerhalb des Cluster-Dendrogramms als Boxen dargestellt.

\subsubsection{Komplexe $n-G r a m m e$}

Die signifikantesten komplexen n-Gramme auf Rang 1 und Rang 2 deuten auf Präpositionalphrasen im Umfeld des Lexems Angst, das selbst im jeweiligen nGramm enthalten ist, hin:

ART Angst APPR ART (LLR: 4871),

APPR Angst APPR ART (LLR: 2391).

17 R Core Team (2017): R: A language and environment for statistical computing. R Foundation for Statistical Computing, Vienna, Austria. URL: https://www.R-project.org/ (zuletzt aufgerufen am 10.08.2020). 
In Kapitel 3 wurde bereits Filatkina (2015 und 2017) zitiert, die auf der Basis ihrer Studien schlussfolgert, dass für das Lexem Angst Präpositionalphrasen mit vor + Objekt, die auf den Gegenstand der Angst verweisen, charakteristisch sind. So überwiegt in den Realisierungsformen der beiden komplexen n-Gramme ebenfalls die Präposition vor, deutlich seltener sind um und in belegt. Auf welche Gegenstände die Präposition vor verweist, wurde bereits anhand des Suchmusters Angst vor NN/NE verdeutlicht.

Auf dem dritten Rang der signifikantesten n-Gramme befindet sich:

Angst \$, KOUS PPER ${ }^{18}$ (LLR: 1615).

Dabei wird die unterordnende Konjunktion (KOUS) durch folgende Wortformen realisiert (jeweils mit absoluter Frequenz): dass (662), wenn (64), weil (57), als (21), wie (11), ob (6), indem (4), obwohl (3), da (2), damit (2), während (1), zumal (1), sobald (1). So stellt der dass-Satz als häufigste Form das Komplement zum Nomen Angst dar. ${ }^{19}$ Außerdem lässt sich die bereits angeführte Beobachtung Filatkinas (2017), dass im Umfeld von Zukunftsangst häufig Adversativ- und Konzessivsätze auftreten, die etwa durch wenn, obwohl oder trotz eingeleitet werden, auf das Lexem Angst erweitern. Darüber hinaus sind, bezogen auf die unterordnende Konjunktion, auch kausale und konditionale sowie ferner instrumentale, finale und temporale Bedeutungsrelationen in den Realisierungsformen des n-Gramms belegt, die im Folgenden z. T. exemplarisch illustriert werden sollen.

So dienen die dass-Sätze dazu, die Angst auf einen Gegenstand einzuschränken bzw. auszurichten. Im Gegensatz zur Präpositionalphrase mit vor, die in der Folge des Lexems Angst ebenfalls auf die Gegenstände verweist, erlaubt die Darstellung im Gliedsatz unter Umständen eine umfangreichere Beschreibung mit dem Fokus auf Handlungen und möglichen Folgen, die Angst auslösen. So findet sich in Beispiel (14) eine parataktische Reihung zweier Gegenstände der Angst mancher Eltern. Darüber hinaus kann die Angst davor, dass die Kinder den Anschluss verpassen, als Folge des ersten Gegenstands, dass den Kindern nicht genug geholfen werden kann, verstanden werden. Somit zeigt sich,

18 Das Zeichen „\$,“ bedeutet, dass ein Komma vorliegt.

19 Dementsprechend ist es nicht überraschend, dass Angst in der folgenden Liste des IDS geführt wird: Nomina mit dass-Satz als Komplement. In: Institut für Deutsche Sprache: „Systematische Grammatik“. Grammatisches Informationssystem grammis. DOI: 10.14618/grammatik-system. Unter: https://grammis.ids-mannheim.de/systematische-grammatik/5097 (zuletzt aufgerufen am 10.08.2020). 
dass dass-Sätze im Rahmen der Darstellung des Gegenstands der Angst sehr produktiv sind. Zugleich sind sie im Vergleich zu Präpositionalphrasen ungleich schwerer quantitativ zu analysieren, da die Realisierungsformen vielseitig sind.

(14) Manche Eltern hätten Angst, dass sie ihren Kindern nicht gut genug helfen und dass sie den Anschluss verpassen durch die Corona-Krise, erzählen die Lehrerinnen. (DIE ZEIT, 04.05.2020)

Wenn-Sätze beziehen sich hingegen auf eine bestimmte Bedingung bzw. einen Umstand, die bzw. der Angst erzeugt. So bezieht sich der wenn-Satz in Beispiel (15) auf den Umstand, im öffentlichen Raum unterwegs zu sein, womit die Nutzung von öffentlichen Verkehrsmitteln, Straßen und Plätzen gemeint ist, wie aus dem weiteren Kontext zu schließen ist. Interessant ist in diesem Beispiel zudem, dass über die konzessive Präpositionalphrase mit trotz eine negative Jetzt-Situation konstruiert wird, die anschließend über das Ergebnis der Umfrage, dass die große Mehrheit der Deutschen keine Angst empfinde, widerlegt wird. Dies stellt einen Gegensatz zu Filatkinas (2017) Ausführungen dar, die, wie bereits erwähnt, für Zukunftsangst im Rahmen von Konzessivsätzen Belege ausgehend von einer positiven Jetzt-Situation aufführt. Grundsätzlich wäre es demnach interessant, die Belege auf beide inhaltliche Verweisrichtungen hin $\mathrm{zu}$ prüfen. Dies würde jedoch den Umfang des vorliegenden Beitrages übersteigen.

(15) Trotz der Debatte über eine stärkere Überwachung des öffentlichen Raums empfindet die große Mehrheit der Deutschen keine Angst, wenn sie unterwegs sind. Das ergab eine repräsentative Umfrage von Infratest Dimap im Auftrag der NDR-Sendung Panorama. (DIE ZEIT, 06.02.2017)

Unterordnende Konjunktionen spielen im unmittelbaren sowie im weiteren Umfeld des Lexems Angst insgesamt eine wichtige Rolle. Gleich drei Gruppen, die aus der Clusteranalyse der n-Gramme hervorgegangen sind, enthalten nahezu ausschließlich n-Gramme mit einer unterordnenden Konjunktion (KOUS). Insgesamt sind 161 verschiedene $\mathrm{n}$-Gramme in diesen Gruppen enthalten und lediglich ein n-Gramm (wissen PTKNEG \$, PWS) weist keine unterordnende Konjunktion auf. Im Folgenden wird jeweils ein Auszug der n-Gramme aus den einzelnen Gruppen aufgeführt. 


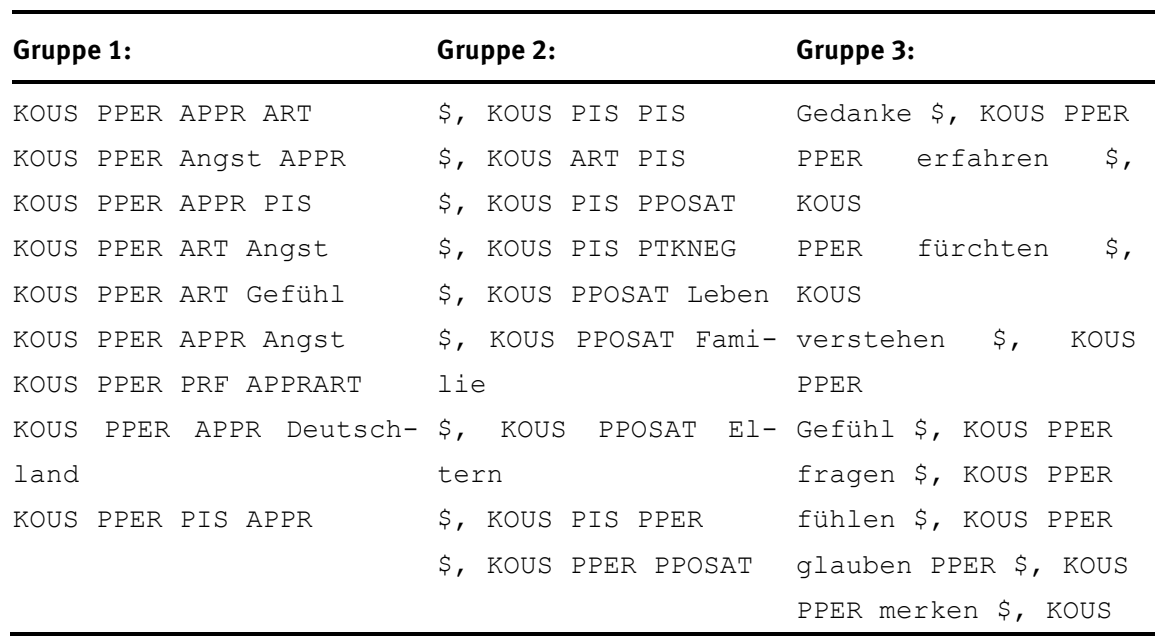

Dabei soll zunächst exemplarisch auf das folgende n-Gramm genauer eingegangen werden:

KOUS PPER Angst APPR (LLR: 385),

das mit einer absoluten Frequenz von 198 in den Daten belegt ist. So besitzt die unterordnende Konjunktion in Beispiel (16), das eine Realisierungsform des nGramms wiedergibt, eine kausale Bedeutungsdimension. Die Angst vor Anschlägen wird neben der Angst, angegriffen zu werden, als eine Reihe von Gründen aufgeführt, die viele dazu bewegen, nicht am Gedenkmarsch ausgehend vom Platz der Republik als Reaktion auf das Attentat in der Redaktion der Satirezeitschrift Charlie Hebdo teilzunehmen.

(16) Natürlich gibt es auch viele, die heute ganz bewusst nicht zu dem Großereignis gekommen sind. Einige wohl, weil sie - wie ein Karikaturist von der Place du Tertre am Samstag - finden, dass der Koran nicht zu Frankreich passe und alle, die an den glauben, gehen könnten. Weil sie sich nicht vom politischen Symbol-Geheische vereinnahmen lassen wollen. Weil sie Angst vor Anschlägen haben. Weil sie Angst haben, angegriffen zu werden: als Moslem von anders- oder gar nicht gläubigen Franzosen; als Moslem von anderen Moslems. (DIE ZEIT, 11.01.2015)

Das Personalpronomen (PPER) sie bezieht sich in Beispiel (16) auf ein weitgehend unbestimmtes Kollektiv, das sich aus den Menschen zusammensetzt, die 
bewusst nicht zu dem Großereignis gekommen sind. Auf dieses Kollektiv, das nicht explizit genannt wird, wird zuvor durch das substituierende Indefinitpronomen (PIS) viele referiert, das ebenfalls zu dessen Unbestimmtheit beiträgt. Sie ist die häufigste Realisierungsform für das Personalpronomen des n-Gramms KOUS PPER Angst APPR mit einer absoluten Frequenz von 111. Zumeist bezieht es sich, wie im zuvor thematisierten Beispiel, auf den Plural und referiert auf Kollektive. Dies erscheint wenig überraschend, da Filatkina (2015) bereits auf Kollektiva in der Form von Attributen zum Lexem Zukunftsangst hingewiesen hat, die der Dramatisierung des Ausmaßes dienen. Weit hinter der Realisierungsform sie liegen die Formen er (34), ich (33), wir (13), du (6) und es (1) - jeweils mit absoluter Frequenz. Dies verdeutlicht, dass im Rahmen der Thematisierung der Gegenstände der Angst über das untersuchte n-Gramm zumeist auf Kollektive und seltener auf Einzelpersonen als Träger der Angst Bezug genommen wird.

Neben Personalpronomen sind besonders in Gruppe zwei der signifikanten n-Gramme mit unterordnender Konjunktion ebenfalls Indefinitpronomen (PIS) bzw. generalisierende Personalpronomen und attribuierende Possessivpronomen (PPOSAT) anzutreffen. Dabei ist das Referenzobjekt der Indefinitpronomen, wie bereits im Rahmen von Beispiel (16) verdeutlicht wurde, bei den Realisierungsformen viele und man weitgehend unbestimmt. So bezieht sich die Realisierung man in Beispiel (17) auf die Partei Die Linke, wie aus dem Kontext geschlossen werden kann. Der Bezug bleibt dennoch unspezifisch in dem Sinne, ob die gesamte Partei oder eine bestimmte Personengruppe gemeint ist. Außerdem ist in der Aussage, dass es schön sei, wenn man etwas zu sagen hat und weniger schön, wenn man Angst hat, etwas Falsches zu sagen ein gewisser Allgemeinheitsgrad im Sinne einer Generalisierung erkennbar.

(17) Die Linke ist jetzt [...] die Oppositionsführerin in Deutschland. [...] Das beschert den Linken neue Aufmerksamkeit - schön, wenn man etwas [KOUS PIS PIS] zu sagen hat; weniger schön, wenn man Angst hat, etwas Falsches zu sagen. (DER SPIEGEL, 10.05.2014, Ergänzung durch C.G.)

Im Gegensatz zu den Indefinitpronomen beziehen sich die attribuierenden Possessivpronomen (PPOSAT) auch auf persönliche Schilderungen im Zusammenhang mit Angst. Eine Sichtung der Belege ergibt, dass häufig persönliche Erfahrungsberichte in der Ich-Form zitiert werden, wie Beispiel (18) illustriert. Der Auszug stammt aus einem Artikel über Glück im Alter. Dabei hat ZEIT ONLINE Zuschriften von Leserinnen und Lesern u. a. zur Frage, welche Erfahrungen sie mit dem Alter gemacht haben, gesammelt. In seinem Erfahrungsbericht thema- 
tisiert der Leser die Angst nicht direkt, spricht aber im Sinne negativer Zukunftserwartungen von ehemaligen Bedenken, wie sein Leben sich als Rentner gestalten wird. Direkt im Anschluss spricht er von einer Sinnkrise, die er fürchtete. Somit wird die Furcht bzw. Angst ${ }^{20}$ direkt mit den negativen Zukunftserwartungen in Verbindung gebracht. Im weiteren Verlauf wird jedoch darauf verwiesen, dass sich die Erwartungshaltung nicht bestätigt hat und der Leser in seiner Situation als Rentner ziemlich happy ist.

(18) $\mathrm{Zu}$ wünschen wäre allen, dass es ihnen ergeht wie jenem ZEIT ONLINELeser, der schreibt: „Ich hatte Bedenken, wie mein Leben [\$, KOUS PPOSAT Leben] als Rentner sich gestalten wird. Ich fürchtete, in eine veritable Sinnkrise zu fallen. Mit einiger Erleichterung stelle ich fest, dass dem nicht so ist. Ich sitze in der Früh beim Frühstück und stelle fest: ich bin ziemlich happy. [...]“ (DIE ZEIT, 13.06.2018, Ergänzung durch C.G.)

Auf der Basis der vorangegangenen Ausführungen wird deutlich, dass Angst im publizistischen Diskurs sowohl häufig nicht näher spezifizierten Kollektiven zugeschrieben wird als auch im Rahmen von zitierten individuellen Erfahrungsberichten Teil des persönlichen Emotionsausdrucks ist.

Schließlich soll auf die dritte Gruppe der n-Gramme Bezug genommen werden. Anhand dieser Gruppe kann die Einsicht gewonnen werden, welche Nomen und Vollverben der Konstruktion \$, KOUS PPER vorangehen. Dabei sind die folgenden zwei Konstruktionen belegt:

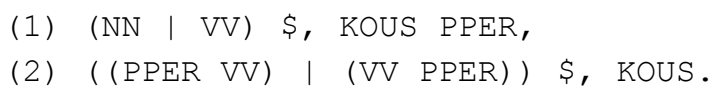

Berücksichtigt man alle Nomen und Vollverben in Gruppe drei, die der unterordnenden Konjunktion vorangestellt sind, so finden sich Verben, die auf Erkenntnisprozesse bzw. Gedanken (diese Kategorie ist zugleich auch als Nomen im n-Gramm belegt) verweisen: lernen, glauben, überlegen, fürchten, fragen und verstehen. Zudem finden sich Verben, die auf physische Erfahrungen und z. T. auf Gefühle (wobei diese Kategorie wiederum als Nomen belegt ist) verweisen: sehen, leben, kommen, machen, spüren und fühlen. Schließlich nehmen die Verben merken und erfahren eine Zwischenstellung zwischen den beiden Polen ein. Da die Untersuchungen keine Aussagen zur typischen Abfolge der n-Gramme

20 Im vorliegenden Beitrag gebrauche ich die Begriffe Furcht und Angst synonym, da in der Alltagssprache i. d. R. nicht zwischen den beiden Begriffen unterschieden wird. 
erlauben, lässt sich nicht feststellen, ob das Lexem Angst stets im durch KOUS eingeleiteten Folgesatz belegt ist. Somit lässt sich lediglich schlussfolgern, dass im Umfeld des Lexems Angst auf persönliche oder kollektive Erkenntnisprozesse und physische bzw. gefühlsmäßige Erfahrungen referiert wird.

Neben den drei Gruppen, die als gemeinsames Merkmal eine unterordnende Konjunktion enthalten, ist eine weitere sehr homogene Gruppe belegt. In dieser befinden sich insgesamt 34 verschiedene $n$-Gramme, die in jedem Fall eine Negationspartikel enthalten. Interessant ist dabei, dass als Vollverb in dieser Gruppe ausschließlich wissen belegt ist. Im Folgenden werden die insgesamt fünf n-Gramme mit wissen wiedergegeben:

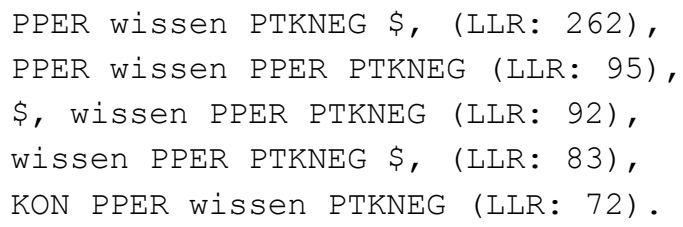

Somit wird das Nicht-Wissen als unsichere Zukunftserwartung thematisiert, wie Beispiel (19) verdeutlicht:

(19) Wie es weiter geht? Ich weiß es nicht, und das bereitet mir Bauchschmerzen. (DIE ZEIT, 20.03.2020)

Hierbei handelt es sich wiederum um ein Zitat einer Zuschrift eines Lesers oder einer Leserin auf die Frage hin, welche Auswirkungen die Maßnahmen gegen die Ausbreitung des Coronavirus auf das Leben der bzw. des Befragten haben. Im Rahmen des Artikels werden insgesamt 30 Zuschriften wiedergegeben. Sie sind auf der Website ${ }^{21}$ als interaktive ,Kacheln' sichtbar, die zunächst einen Satz enthalten und nach einem Klick die vollständige Zuschrift wiedergeben. In der Überschrift des interaktiven Artikels wird ebenfalls ein Zitat aus einer Zuschrift wiedergegeben: „Ich weiß nicht, wie ich meine Familie jetzt ernähren kann“. Auch dieses enthält das Verb wissen in Verbindung mit der Negationspartikel. Eine ähnliche Serie an Erfahrungsberichten, die mit „Elf Protokolle der Unsi-

21 Abrufbar unter: https://www.zeit.de/arbeit/2020-03/corona-krise-pandemie-deutschlandexistenzen-wirtschaft-leserstimmen (zuletzt aufgerufen am 13.08.2020). 
cherheit" betitelt wird, findet sich auch im SPIEGEL. ${ }^{22}$ Das folgende Beispiel (20) bezieht sich auf die Aussage einer Unternehmerin:

(20) Das Stadtmarketing hat jetzt die Idee, einen gemeinsamen Lieferservice der Einzelhandelsgeschäfte zu organisieren, unter dem Motto: Ihr kauft in Vreden - wir liefern. Aber ob das mit den Lieferungen an Privatkunden künftig noch lange möglich ist wissen wir nicht, wie wir so vieles nicht wissen. Wir können nur hoffen, dass es schnell vorbeigeht. (DER SPIEGEL, 18.03.2020)

In beiden Fällen bezieht sich die Aussage des Nicht-Wissens auf eine unsichere Situation in der Gegenwart, deren Ausgang offen ist - demnach ist die ausgedrückte Unsicherheit in die Zukunft gerichtet. Mit Bezug auf das Nicht-Wissen folgt in Beispiel (19) der Phraseologismus, dass dies Bauchschmerzen bereite. Somit wird erneut die Unsicherheit betont. In Beispiel (20) schließt sich unmittelbar an die Feststellung des Nicht-Wissens die generalisierende Aussage an, dass wir so vieles nicht wissen. Dies bezieht sich vermutlich auf die vielfältigen Auswirkungen der Corona-Pandemie, die kaum vorhersehbar sind. Es wird deutlich, dass Nicht-Wissen Unsicherheit und somit auch Angst erzeugt - auch wenn sich das Lexem Angst nicht im unmittelbaren Umfeld des n-Gramms wiederfindet. Bergmann (2002: 3f.) stellt in diesem Zusammenhang fest, dass sowohl Nicht-Wissen als auch Wissen Angst erzeugen können „[...] - vielleicht weil sich auf der Rückseite eines Wissenszuwachses immer wieder neue Felder des Nicht-Wissens eröffnen.“ (ebd.: 4)

\subsubsection{Lemma-n-Gramme}

Im Gegensatz zu den komplexen n-Grammen bestand das Ziel bei der Berechnung der Lemma-n-Gramme nicht ausschließlich darin, charakteristische Konstruktionen im Umfeld des Lexems Angst zu ermitteln. Darüber hinaus sollte geprüft werden, ob sich für bestimmte Zeitabschnitte einzigartige Angstkonstruktionen finden lassen, die unter Umständen auf eine neue Angstkultur verweisen. Im Folgenden soll dabei aufgezeigt werden, welche Lemma-n-Gramme

22 Abrufbar unter: https://www.spiegel.de/wirtschaft/unternehmen/corona-krise-und-kleinunternehmer-viele-reserven-habe-ich-nicht-mehr-a-18ef8b37-8064-4ad5-b30f-fdd08a10a6d7 (zuletzt aufgerufen am 13.08.2020). 
im Umfeld des Lexems Angst aus dem Jahr 2020 sich signifikant von jenen aus den Vorjahren (bis einschließlich 2013) unterscheiden.

So stellt die Coronavirus-Pandemie, die das Jahr 2020 prägt, eine Ausnahmesituation dar, die besonders in der frühen Phase mit Unsicherheit verbunden war, da wenig über das neuartige Virus bekannt war. In diesem Zusammenhang erscheint es wenig überraschend, dass als signifikanteste n-Gramme

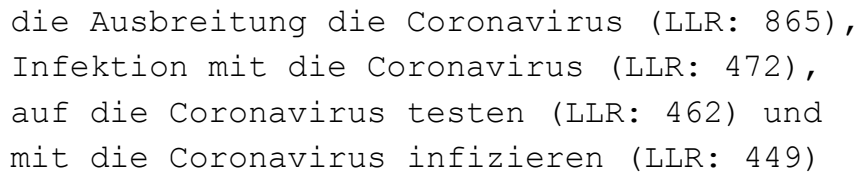

erscheinen. Ferner sind n-Gramme in einer Gruppe zusammengefügt, die auf eine Kriegsmetaphorik in Bezug auf die Thematisierung von Maßnahmen zur Eindämmung des Virus verweisen: Kampf gegen die Ausbreitung, Kampf gegen die Virus, Maßnahme in+die Kampf gegen, Maßnahme zu+die Bekämpfung die sowie Kampf gegen die CoronaPandemie.

Die Einschränkungen aufgrund der Schutzmaßnahmen gegen das Virus, das sich rasant weltweit verbreitete, betrafen einen Großteil der Bevölkerung in Deutschland. Am deutlichsten sah sich jeder bzw. jede Einzelne mit der Konsequenz konfrontiert, möglichst $\mathrm{zu}$ Hause $\mathrm{zu}$ bleiben, um soziale Kontakte weitgehend zu vermeiden. Auch diese zentrale Maßnahme ist in den signifikanten n-Grammen als Gruppe belegt:

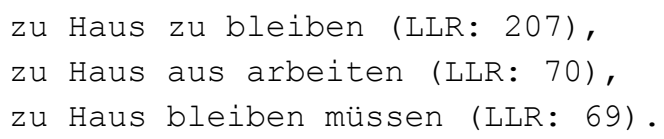

Mehrere Gruppen von Lemma-n-Grammen verweisen auf die Thematisierung der Zahlen bzw. des Anteils der Infizierten, die somit im gegenwärtigen publizistischen Diskurs eine wichtige Rolle einnimmt. Dabei wird die Zuverlässigkeit betont, indem von offiziellen, bestätigten und nachgewiesenen Zahlen bzw. Fällen, aber auch Infizierten und Toten gesprochen wird. Über das den Zahlen vorangestellte mehr als oder mindestens wird auf eine Dunkelziffer verwiesen, die wahrscheinlich höher als die gemeldeten Fälle ist. Die im Verborgenen liegende tatsächliche Zahl der Fälle kann wiederum Unsicherheit und Angst erzeugen. Außerdem werden die Zahlen in Relation zu den Einwohnern der Länder oder 
Bundesländer gesetzt und es wird darauf eingegangen, wie sich die Zahlen entwickeln - ob sie etwa steigen.

\begin{tabular}{ll}
\hline Gruppe 1: & Gruppe 2: \\
\hline die offiziell gemeldet Zahl & mehr als dcarde bestätigt \\
die Zahl die nachgewiesen & mehr als @carde nachgewiesen \\
die Zahl die Neuinfektion & Veranstaltung mit mehr als \\
Zahl die bestätigt Infektion & Nordrhein-Westfalen mit mehr \\
die Zahl die Todesfall & als \\
Zahl die bestätigt Fall & mit mehr als @carde \\
steigen die Zahl die & mehr als @card@ Infektion \\
die offiziell Zahl die & mehr als @card@ Todesfall \\
Zahl die Bundesland berücksichti- & mehr als an+die Vortag \\
gen & mehr als @card@ Mensch \\
Zahl die Infizierte steigen & dcarde mehr als an+die \\
Zahl die Infizierte beziehen & mehr als @card@ Infizierte \\
offiziell gemeldet Zahl die & Baden-Würtemberg mit mehr als \\
offiziell Zahl die Tote & auf mehr als @card@ \\
die Zahl die Infektion &
\end{tabular}

\section{Gruppe 3:}

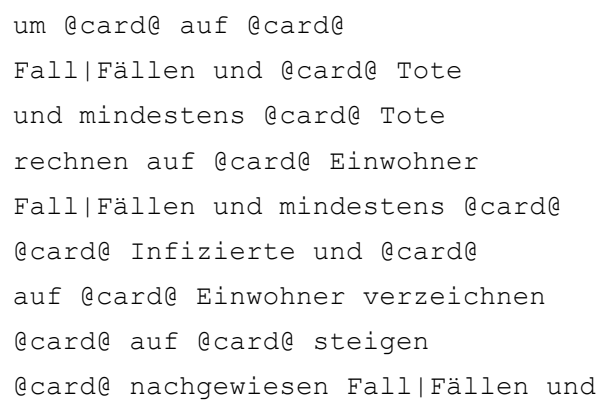

Insgesamt ist das ,Durchschlagen“ der obigen drei Gruppen in den Daten nachvollziehbar, da sowohl im SPIEGEL als auch in der ZEIT Sonderseiten zur Entwicklung der Corona-Pandemie und somit auch zur Anzahl der Fälle in 
Deutschland und weltweit angelegt wurden, die täglich aktualisiert werden und auf die im Rahmen anderer Artikel referiert wurde und wird. ${ }^{23}$

Man sollte sich bezüglich der vorangegangenen Ergebnisse noch einmal vergegenwärtigen, dass stets das Lexem Angst im Umfeld belegt ist. Somit steht das Angstmanagement im Rahmen des publizistischen Diskurses im Vordergrund. Mögliche Ängste vor dem Virus werden thematisiert, wie auch die folgenden signifikanten $\mathrm{n}-\mathrm{Gramme}$ nahelegen:

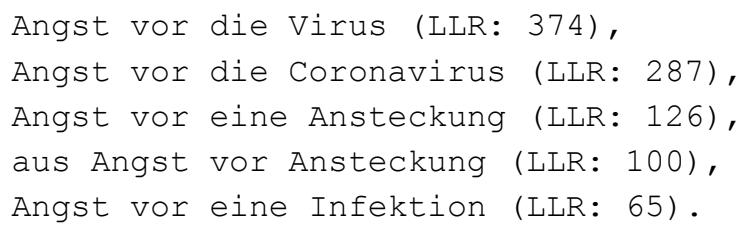

Das Angstmanagement der beiden Medien verfolgt dabei das Ziel der Angstminderung, indem der Kampf gegen das Virus allgemein und Maßnahmen zur Bekämpfung, wie etwa das Zu-Hause-Bleiben, thematisiert werden. Außerdem wird im Rahmen des Angstmanagements umfassend über die Zahl der Infizierten, Genesenen und Toten sowie über die Entwicklung der Zahlen in Deutschland und weltweit informiert. Damit steht das Wissen über die Ansteckungsrate und auch über das Virus selbst im Vordergrund, das - wie die Ausführungen von Bergmann (2002) nahelegen - wiederum Angst erzeugen kann. Somit bewegt sich der Mediendiskurs im Kontext des Lexems Angst für das Jahr 2020, wie auch Köstler (2011: 216f.) und Steinseifer (2007: 299) unabhängig voneinander im Hinblick auf themenspezifische Diskurse aus anderen Zeiträumen festgestellt haben, zwischen den Polen der Angstmehrung und Angstminderung.

Da auf diese Weise trotz der intendierten Angstminderung Unsicherheiten bestehen bleiben, führt dies schließlich zur offenen Frage, ob und wie die Pandemie zu bewältigen ist. Diese Frage ist auch in den signifikanten n-Grammen als Teil einer Gruppe belegt:

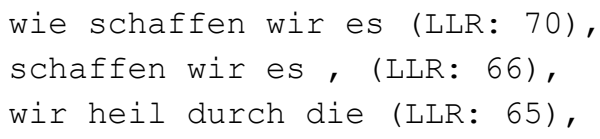

23 Sonderseite der ZEIT: https://www.zeit.de/wissen/gesundheit/coronavirus-echtzeit-kartedeutschland-landkreise-infektionen-ausbreitung sowie Sonderseite des SPIEGELS: https:// www.spiegel.de/wissenschaft/medizin/coronavirus-infizierte-genesene-tote-alle-live-daten-a242d71d5-554b-47b6-969a-cd920e8821f1 (jeweils zuletzt aufgerufen am 14.08.2020). 
aber wie schaffen wir (LLR: 65),

wie kommen wir heil (LLR: 65),

heil durch die Alltag (LLR: 65).

Die n-Gramme weisen nur eine geringe Frequenz auf und sind im Wesentlichen auf die SPIEGEL-Themenseite „Kollateralfragen“ zum Coronavirus zurückzuführen. Im Folgenden wird die Beschreibung der Themenseite wiedergegeben:

(21) Die Krise stellt unser aller Leben auf den Kopf. Natürlich geht es erst einmal darum, gesund zu bleiben. Aber wie schaffen wir es, dass auch die Beziehung und die Familie intakt bleiben? Wie kommen wir heil durch den Alltag? Hier beantworten Experten ab sofort regelmäßig Fragen von Leserinnen und Lesern $\mathrm{zu}$ diesen Themen. (DER SPIEGEL, Themen-Seite unter: https://www.spiegel.de/thema/coronavirus-familie-beziehungtipps-kollateralfragen/, zuletzt aufgerufen am 12.08.2020)

Leserinnen und Leser werden auf dieser Themenseite dazu aufgerufen, ihre persönlichen Fragen per E-Mail zu stellen. Die obigen n-Gramme sind dabei Teil von Fragen mit generalisierendem Charakter, die sich auf mögliche Probleme in der Beziehung, der Familie oder ganz allgemein im Alltag in Folge der CoronaKrise beziehen. Diese sollen die Leserinnen und Leser dazu anregen, eigene bzw. individuelle Fragen zu formulieren.

Darüber hinaus ist interessant, dass etwa das n-Gramm wie schaffen wir es nahezu ausschließlich für das Jahr 2020 belegt ist. So findet es sich im SPIEGEL über dieses Jahr hinaus lediglich einmal für das Jahr 2016. In der ZEIT ist es im Jahr 2019 fünfmal und im Jahr 2020 dreimal belegt. Das folgende Zitat aus der ZEIT bezieht sich auf eine Aussage des CDU-Politikers Friedrich Merz:

(22) Europa war schon vor Corona in einer äußerst schwierigen Lage. Die größte Herausforderung ist aus meiner Sicht: Wie schaffen wir es, Europa wieder so voranzubringen, dass es neben den USA und China einer der drei großen Wirtschaftsräume der Welt bleiben kann? Das wird eine enorme Kraftanstrengung. Wir müssen in Deutschland wissen: Wir sind wie wenige andere auf Europa angewiesen. (DIE ZEIT, 02.05.2020)

Das obige n-Gramm ist Teil der offenen Fragestellung und zugleich größten Herausforderung, wie Europa als bedeutsamer Wirtschaftsraum bestehen bleiben kann. Dabei wird deutlich, dass sich das Personalpronomen wir als Teil des $\mathrm{n}$-Gramms wiederum auf ein weitgehend unbestimmtes Kollektiv bezieht. Somit 
bleibt unklar, ob Merz in erster Linie die Politikerinnen und Politiker oder die Bevölkerung in Deutschland insgesamt thematisiert, wobei er Teil beider Kollektive ist. Auf die Frage folgt die Feststellung, dass eine enorme Kraftanstrengung nötig sein wird. Schließlich erfolgt der explizite Verweis auf das nach Merz nötige Wissen bzw. Bewusstsein um die Angewiesenheit Deutschlands auf Europa. Auf diese Weise wird indirekt - über den Bezug zur äußerst schwierigen Lage Europas als Wirtschaftsraum - Unsicherheit thematisiert und möglicherweise auch erzeugt.

Insgesamt konnten die Untersuchungen $\mathrm{zu}$ den n-Grammen zahlreiche Ergebnisse der vorangegangenen Studien zu Angstkonstruktionen aus Kapitel 3 stützen und erweitern. So sind Präpositionalphrasen charakteristisch zur Benennung des Gegenstandes der Angst. Darüber hinaus werden die Gegenstände auch in dass-Sätzen als Komplemente des Nomens Angst beschrieben. Dies erklärt z. T. die wichtige Rolle unterordnender Konjunktionen im Umfeld des Lexems Angst, die zudem vor allem in kausalen und konditionalen Bedeutungsrelationen belegt sind. Angst wird somit auch als mögliche Ursache oder Folge einer Situation, einer Handlung oder eines Handlungsrahmens thematisiert. Darüber hinaus wird im Umfeld des Lexems Angst auf persönliche oder kollektive Erkenntnisprozesse und physische bzw. gefühlsmäßige Erfahrungen referiert. Außerdem führen Verweise auf Nicht-Wissen aber auch auf Wissen zu einer für den publizistischen Diskurs charakteristischen Auseinandersetzung zwischen den Polen der Angstmehrung und Angstminderung. Schließlich konnten für das Jahr 2020 charakteristische Angstkonstruktionen ermittelt werden, die möglicherweise eine neue Angstkultur konstituieren. So ist das Coronavirus der zentrale Gegenstand der Angst, den es zu bekämpfen gilt. Bei den Maßnahmen zur Angstminderung spielen Informationen und damit Wissen eine zentrale Rolle. Im Sinne einer Angstspirale kann die Angst jedoch auf diese Weise auch verstärkt werden, sodass die Angst auch fortwährend Teil des publizistischen Diskurses bleiben wird.

\section{Fazit}

Abschließend lässt sich festhalten, dass sich die im vorliegenden Beitrag vorgestellte korpuspragmatische Methode in besonderer Weise dazu eignet, die Grammatik der Angst um weitere Konstruktionen zu ergänzen. So können die Erkenntnisse vorangegangener Studien zu einem großen Teil durch die Ergebnisse der vorliegenden Analyse bestätigt und darüber hinaus ergänzt und vertieft werden. Die identifizierten Muster als potentielle Angstkonstruktionen stellen in Anlehnung an Filatkina (2017) sprachliche Mittel aus dem lexikalisch- 
semantischen, (morpho-)syntaktischen sowie textuellen und diskursiven Bereich dar. Entsprechend umfangreich ist die Deutung der Muster auf der Basis der Textbelege, die im vorliegenden Beitrag nur exemplarisch und ausschnittartig erfolgen konnte. Beispielsweise kann die Annahme, dass Angst häufig in Paarformeln erscheint, bestätigt und auf Aufzählungen von Gefühlszuständen hin erweitert werden, wobei die Frage nach einer möglichen Ursache-FolgeBeziehung offenbleibt. Unter anderem über die Adjektive irrational und rational in Verbindung mit Angst und semantisch ähnlichen Begriffen zeigt sich anhand mehrerer Belege ein spezifischer Diskurs zur Angemessenheit bzw. Unangemessenheit von Angst sowie ähnlicher Emotionen, der einen wesentlichen Bestandteil der Angstkultur darstellt. Weiterhin konstitutiv für die Angstkultur ist die Zuschreibung von Angst zu Kollektiven als Träger der Angst, die in ihrer Zusammensetzung jedoch vage bleiben. Neben Kollektivbezeichnungen konnten Indefinitpronomen als Marker für unbestimmte Kollektive ermittelt werden. Zudem sind Verweise auf Studien üblich, um die Angst - ebenfalls in Verbindung zu Kollektiven - als zweifellos gegeben darzustellen. Schließlich können Aussagen des Nicht-Wissens, die auf eine unsichere Situation in der Gegenwart hindeuten, als weiterer Bestandteil einer Angstkultur angesehen werden. Die Ergebnisse stützen somit die eingangs formulierte These, dass es sich bei Angst um eine kulturell geprägte Emotion handelt. Über die allgemeine kulturelle Prägung der Angst hinaus werden in den Ergebnissen zu den Lemma-nGrammen Konturen einer aktuellen Angstkultur deutlich. Als zentraler Gegenstand der Angst erscheint in der gegenwärtigen Angstkultur das Coronavirus. Das Angstmanagement im Rahmen der analysierten Zeitungsartikel bewegt sich dabei - mehr oder weniger intendiert - zwischen den Polen der Angstmehrung und Angstminderung. Die Maßnahmen zur Eindämmung des Virus werden z. T. durch eine Kriegsmetaphorik wiedergegeben, die sowohl dramatisierend bzw. angsterzeugend als auch angstmindernd wirken kann. Eine weitere Maßnahme des Angstmanagements im publizistischen Diskurs besteht darin, fortwährend über die gegenwärtigen Zahlen der Infizierten und Toten zu berichten. Dabei kann zum einen der Verweis auf eine Dunkelziffer wiederum angsterzeugend oder angststeigernd wirken. Zum anderen wird eine Angstminderung angestrebt, indem die zunächst hoch erscheinenden Zahlen in Relation zu den Einwohnern der Länder oder Bundesländer gesetzt werden. Schließlich weisen die Ergebnisse auch auf weniger frequente Phänomene hin, wie den Teil der offenen Frage als Anregung für LeserInnenzuschriften: Wie schaffen wir es, die Pandemie zu bewältigen? Dabei tragen - nicht nur in diesem Fall - auch persönliche Schilderungen bzw. Erfahrungsberichte im Zusammenhang mit Angst zu einer Angstkultur bei. 


\section{Literatur}

Bergmann, Jörg (2002): Paradoxien der Angstkommunikation - Über Veralten und Modernität der Angst. Jahrbuch für Gruppenanalyse und ihre Anwendungen, 1-13.

Biess, Frank (2019): Republik der Angst. Eine andere Geschichte der Bundesrepublik. Hamburg: Rowohlt.

Böhme, Hartmut (2000): Leibliche und kulturelle Codierungen der Angst. In: ZDF-Nachtstudio (Hrsg.), Große Gefühle. Bausteine menschlichen Verhaltens, 214-240.

Böhme, Hartmut (2009): Vom phobos zur Angst. Zur Transformations- und Kulturgeschichte der Angst. In: Martin Harbsmeier \& Sebastian Möckel (Hrsg.), Pathos, Affekt, Emotion. Transformationen der Antike, 154-184. Frankfurt (Main): Suhrkamp.

Bubenhofer, Noah (2009): Sprachgebrauchsmuster. Korpuslinguistik als Methode der Diskursund Kulturanalyse. Berlin/ New York: De Gruyter.

Bubenhofer, Noah \& Joachim Scharloth (2013): Korpuslinguistische Diskursanalyse. Der Nutzen empirisch-quantitativer Verfahren. In: Ulrike Hanna Meinhof, Martin Reisigl \& Ingo H. Warnke (Hrsg.), Diskurslinguistik im Spannungsfeld von Deskription und Kritik, 147-167. Berlin: Akademie.

Bubenhofer, Noah (2017): Kollokationen, n-Gramme, Mehrworteinheiten. In: Kersten Sven Roth, Martin Wengeler \& Alexander Ziem (Hrsg.), Handbuch Sprache in Politik und Gesellschaft, 69-93. Berlin/Boston: De Gruyter.

Bubenhofer, Noah, Selena Calleri \& Philipp Dreesen (2019): Politisierung in rechtspopulistischen Medien: Wortschatzanalyse und Word Embeddings. OBST. Osnabrücker Beiträge zur Sprachtheorie 95, 211-241.

Dornseiff, Franz (1959): Der Deutsche Wortschatz nach Sachgruppen. Berlin: De Gruyter.

Filatkina, Natalia (2015): Diskurshistorische Analysen des Begriffs Zukunftsangst anhand des SPIEGEL-ONLINE-Archivs. Sprachwissenschaft 40, 79-126.

Filatkina, Natalia (2017): Sprachliche Konstruktion von Zukunftsangst und Misstrauen in deutschen Medien der Gegenwart. Unveröffentl. Mskr. Trier.

Georgi, Christopher (2018): Zur sprachlichen Thematisierung der Angst in Folge von Terrorismus - Eine datengeleitete Studie. In: Fabian Klinker, Joachim Scharloth \& Joanna Szczęk (Hrsg.), Sprachliche Gewalt. Formen und Effekte von Pejorisierung, verbaler Aggression und Hassrede, 109-134. Stuttgart: Metzler.

Gries, Stefan Th. (2013): Statistics for Linguistics with R. A Practical Introduction. Berlin/Boston: De Gruyter.

Hochschild, Arlie Russell (1979): Emotion Work, Feeling Rules, and Social Structure. AJS 85 (3), 551-575.

Holzinger, Herbert (2018): Mit Angst und Bangen: Korpuslinguistische Untersuchungen zu Strukturen des Typs [mit + Substantiv] in adverbialer Funktion im semantischen Feld der Angst. In: Natalia Filatkina \& Sören Stumpf (Hrsg.), Konventionalisierung und Variation, 229-250. Bern: Peter Lang.

Käuser, Andreas (2010): Angst: Begriff - Diskurs - Medium. In: Werkleitz Gesellschaft e.V./KUNSTrePUBLIK e.V. (Hrsg.), Angst hat große Augen. Halle (Saale) u. a., 15-26.

Käuser, Andreas (2013): Medienkulturen der Angst. In: Lars Koch (Hrsg.), Angst. Ein interdisziplinäres Handbuch, 141-147. Stuttgart u. a.: Metzler. 
Köstler, Sandra (2011): „Sicher ist nur die Angst“. Angstkommunikation als Form sozialer Erwartungsbildung in Medienberichterstattung über Terrorismus. Bielefeld. (Dissertation; online unter: https://pub.uni-bielefeld.de/publication/2459208, zuletzt aufgerufen am 14.08.2020)

Lickhardt, Maren (2013): Narration. In: Lars Koch (Hrsg.), Angst. Ein interdisziplinäres Handbuch, 189-197. Stuttgart u. a.: Metzler.

Linke, Angelika (1998): „... und haben uns köstlich amüsirt“. Eine historisch-pragmatische Miniatur zur sprachlichen Kodierung bürgerlichen Lebensgefühls. In: Dieter Cherubim, Siegfried Grosse \& Klaus J. Mattheier (Hrsg.), Sprache und bürgerliche Nation. Beiträge zur deutschen und europäischen Sprachgeschichte des 19. Jahrhunderts, 234-258. Berlin/New York: De Gruyter.

Linke, Angelika (2009): Sprache, Körper, Siegergesten. Eine Skizze zur historischen Normiertheit von sprachlichem wie körperlichem Gefühlsausdruck. In: Johannes Fehr \& Gerd Folkers (Hrsg.), Gefühle zeigen: Manifestationsformen emotionaler Prozesse, 165-202. Zürich: Chronos.

Linke, Angelika (2011): Signifikante Muster - Perspektiven einer kulturanalytischen Linguistik. In: Elisabeth Wåghäll Nivre, Brigitte Kaute, Bo Andersson, Barbro Landén \& Dessislava Stoeva-Holm (Hrsg.), Begegnungen. Das VIII. Nordisch-Baltische Germanistentreffen in Sigtuna vom 11. bis zum 13.6.2009. Stockholm: Stockholms universitet, 23-44.

Luhmann, Niklas (1990): Ökologische Kommunikation. Kann die moderne Gesellschaft sich auf ökologische Gefährdungen einstellen? 3. Auflage. Opladen: Westdeutscher.

Mikolov, Tomas, Kai Chen, Greg Corrado \& Jeffrey Dean (2013): Efficient Estimation of Word Representations in Vector Space. Computer Science [cs], arXiv:1301.3781.

Müller, Marcus (2015): Sprachliches Rollenverhalten. Korpuspragmatische Studien zu divergenten Kontextualisierungen in Mündlichkeit und Schriftlichkeit. Berlin/Boston: De Gruyter.

Řehůřek, Radim \& Petr Sojka (2010): Software Framework for Topic Modelling with Large Corpora. Proceedings of the LREC 2010 Workshop on New Challenges for NLP Frameworks, 46-50.

Scharloth, Joachim \& Noah Bubenhofer (2012): Datengeleitete Korpuspragmatik. Korpusvergleich als Methode der Stilanalyse. In: Ekkehard Felder, Marcus Müller \& Friedemann Vogel (Hrsg.), Korpuspragmatik. Thematische Korpora als Basis diskurslinguistischer Analysen, 195-230. Berlin/Boston: De Gruyter.

Scharloth, Joachim, David Eugster \& Noah Bubenhofer (2013): Das Wuchern der Rhizome. Linguistische Diskursanalyse und Data-driven Turn. In: Dietrich Busse \& Wolfgang Teubert (Hrsg.), Linguistische Diskursanalyse: neue Perspektiven, 345-380. Wiesbaden: Springer.

Schmid, Helmut (1994): Probabilistic Part-of-Speech Tagging Using Decision Trees. Proceedings of International Conference on New Methods in Language Processing. Manchester/UK.

Schmid, Helmut (1995): Improvements in Part-of-Speech Tagging with an Application to German. Proceedings of the ACL SIGDAT-Workshop. Dublin, Ireland.

Schmieder, Falko (2013): Kommunikation. In: Lars Koch (Hrsg.), Angst. Ein interdisziplinäres Handbuch, 197-205. Stuttgart u. a.: Metzler.

Schröter, Juliane (2016): Vom Handeln zur Kultur. Das Konzept der Praktik in der Analyse von Verabschiedungen. In: Arnulf Deppermann, Helmuth Feilke \& Angelika Linke (Hrsg.), Sprachliche und kommunikative Praktiken, 369-403. Berlin/Boston: De Gruyter. 
Steinseifer, Martin (2007): Zwischen Bombenterror und Baader-Story. Terrorismus als Medienereignis. In: Martin Klimke \& Joachim Scharloth (Hrsg.), 1968. Handbuch zur Kultur- und Mediengeschichte der Studentenbewegung, 289-301. Stuttgart/Weimar: Metzler.

Wengeler, Martin (2019): „Im Moment haben die Vertreter der Angstrhetorik die Lufthoheit“. Diskurslinguistische Untersuchungen zur Konstruktion von Zukunftsangst und Vertrauen in deutschen Printmedien. In: Vedad Smailagić (Hrsg.), Die Leistung der Philologie bei der Deutung der Kultur(en), 95-112. Tübingen: Stauffenburg.

\section{Anhang}

Relative Frequenz pro 100.000 Token des Lexems Angst im Untersuchungskorpus

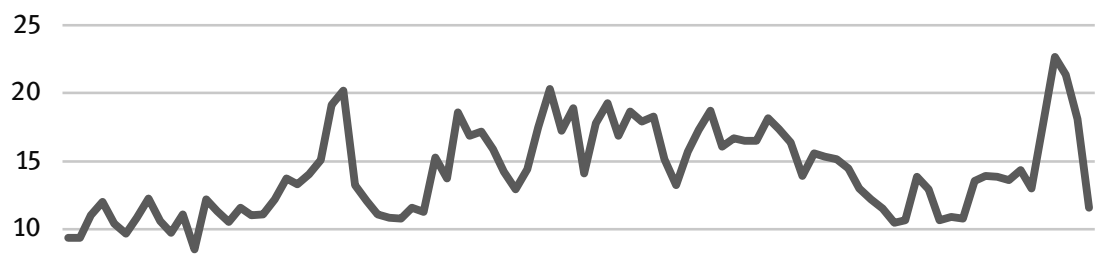

5

0

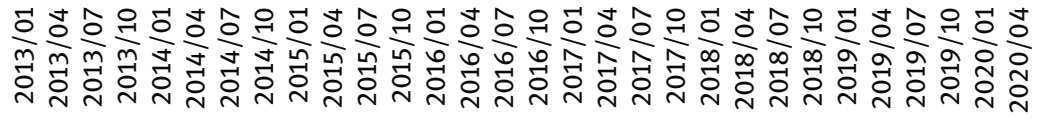

Abb. 1: Frequenzverlauf des Lexems Angst im Untersuchungskorpus 


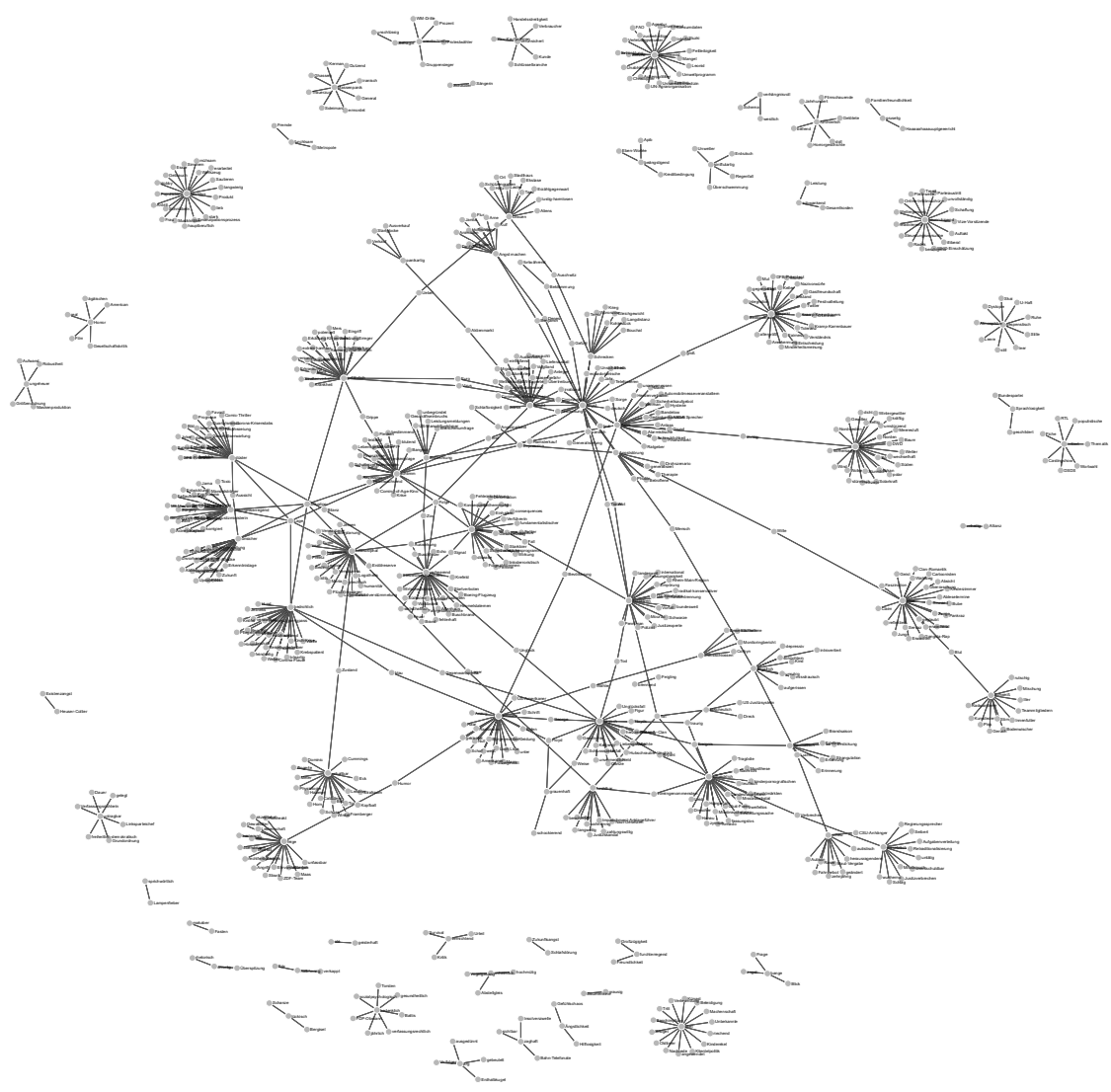

Abb. 2.1: Rhizom des GermaNet-Angstwortschatzes 


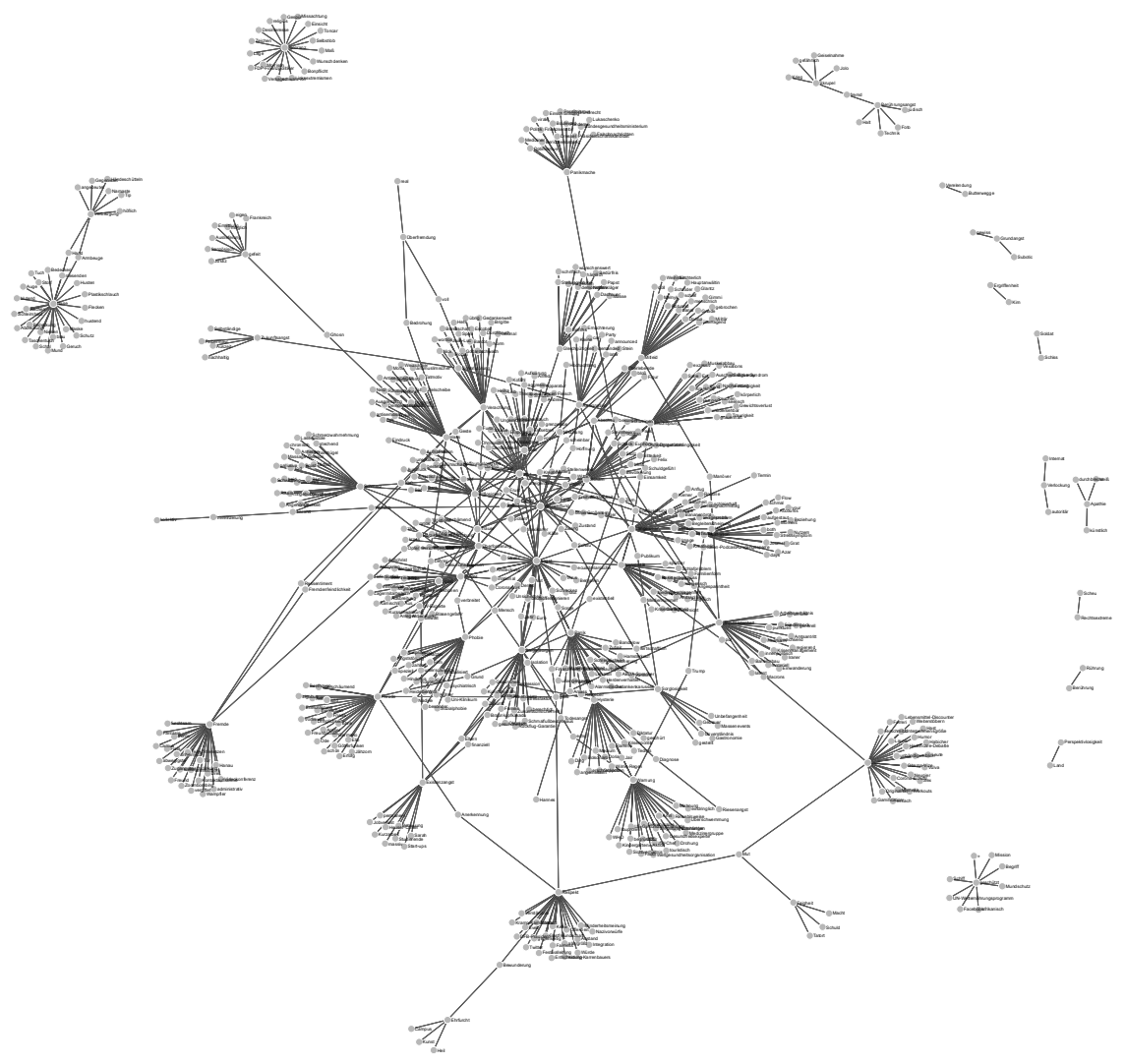

Abb. 2.2: Rhizom des NNs-Angstwortschatzes 


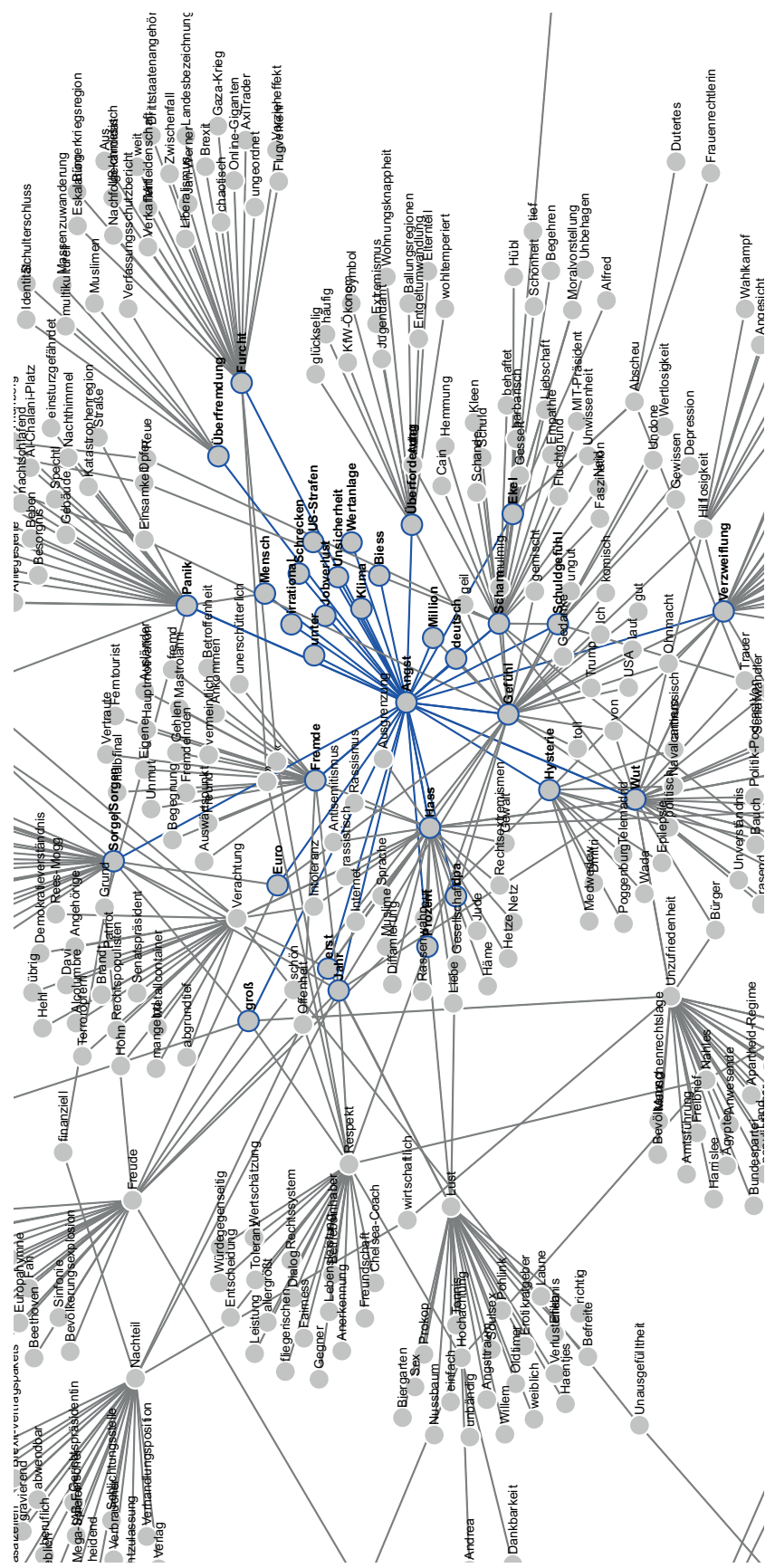

Abb. 3: Rhizomausschnitt für die Kollokationen des Lexems Angst im Jahr 2019 


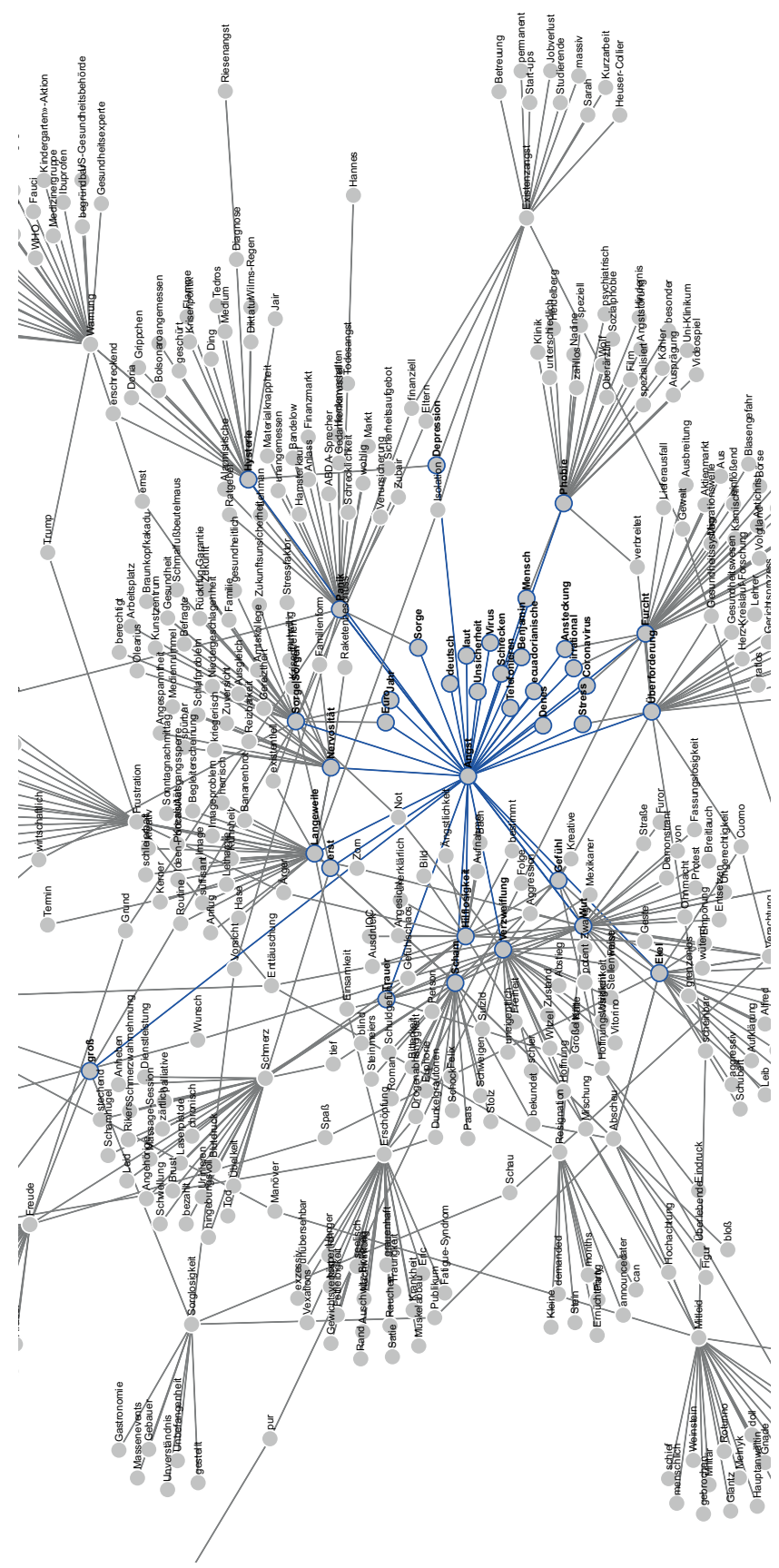

Abb. 4: Rhizomausschnitt für die Kollokationen des Lexems Angst im Jahr 2020 


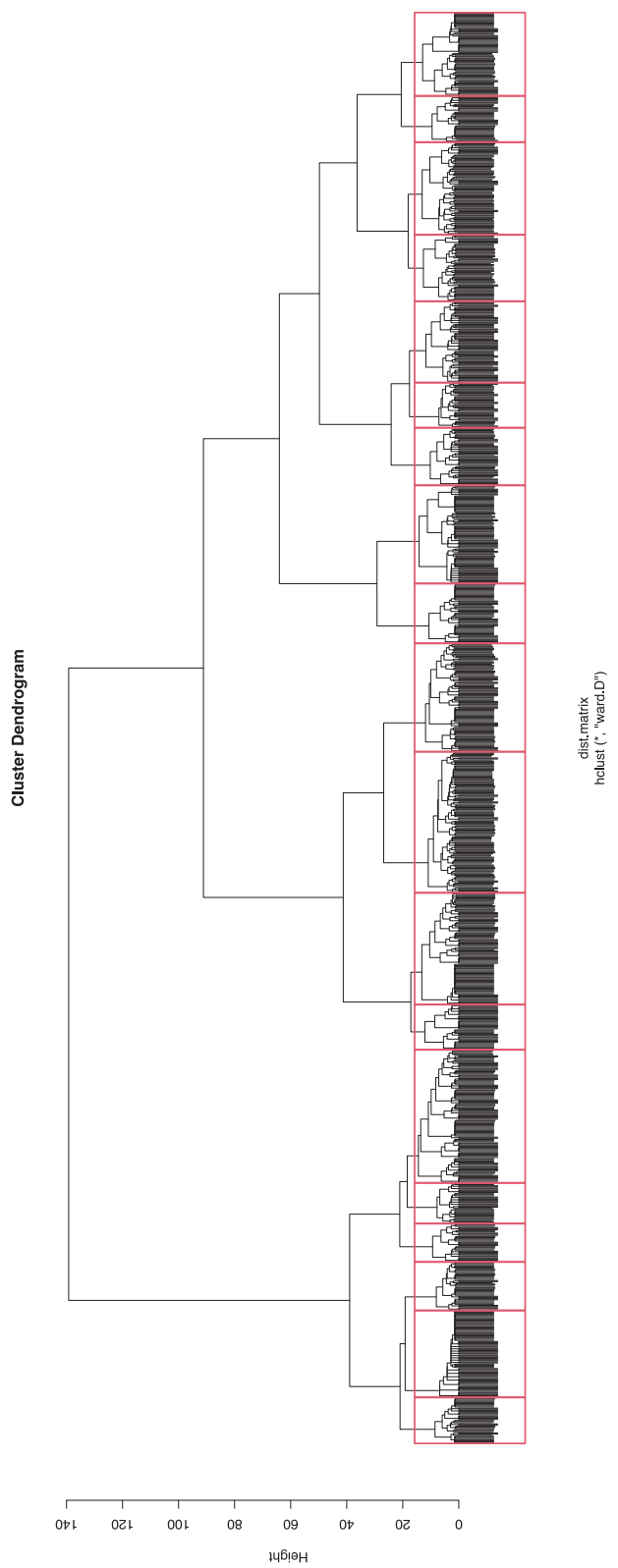

Abb. 5: Cluster-Dendrogramm von komplexen n-Grammen mit Zuordnung zu 19 Gruppen (dargestellt in Boxen) 